\title{
DSCAM Contributes to Dendrite Arborization and Spine Formation in the Developing Cerebral Cortex
}

\author{
Kristen R. Maynard and Elke Stein \\ Department of Molecular, Cellular and Developmental Biology, Cell Biology and Interdisciplinary Neuroscience Program, Yale University, New Haven, \\ Connecticut 06520
}

\begin{abstract}
Down syndrome cell adhesion molecule, or DSCAM, has been implicated in many neurodevelopmental processes including axon guidance, dendrite arborization, and synapse formation. Here we show that DSCAM plays an important role in regulating the morphogenesis of cortical pyramidal neurons in the mouse. We report that DSCAM expression is developmentally regulated and localizes to synaptic plasma membranes during a time of robust cortical dendrite arborization and spine formation. Analysis of mice that carry a spontaneous mutation in DSCAM (DSCAM ${ }^{\text {dell7 }}$ ) revealed gross morphological changes in brain size and shape in addition to subtle changes in cortical organization, volume, and lamination. Early postnatal mutant mice displayed a transient decrease in cortical thickness, but these reductions could not be attributed to changes in neuron production or cell death. DSCAM ${ }^{\text {dell7 }}$ mutants showed temporary impairments in the branching of layer V pyramidal neuron dendrites at P10 and P17 that recovered to normal by adulthood. Defects in DSCAM ${ }^{\text {dell7 }}$ dendrite branching correlated with a temporal increase in apical branch spine density and lasting changes in spine morphology. At P15 and P42, mutant mice displayed a decrease in the percentage of large, stable spines and an increase in the percentage of small, immature spines. Together, our findings suggest that DSCAM contributes to pyramidal neuron morphogenesis by regulating dendrite arborization and spine formation during cortical circuit development.
\end{abstract}

\section{Introduction}

Establishing functional cortical networks requires the precise wiring of neuronal circuits during development. An important step in circuit assembly is the elaboration of pyramidal neuron dendrite arbors and the morphogenesis of dendritic spines (Jan and Jan, 2003; Lippman and Dunaevsky, 2005). Defects in dendrite and spine development have been associated with abnormal cortical wiring in a number of neurological disorders, including mental retardation, autism, and schizophrenia (BenavidesPiccione et al., 2004; Huttenlocher, 1974; Purpura, 1975, Broadbelt et al., 2002; Hutsler and Zhang, 2010; Glantz and Lewis, 2000). While many guidance cues and neurotrophic factors have been implicated in pyramidal neuron dendrite arborization and spine formation (Kim and Chiba, 2004; Tran et al., 2009; Whit-

Received June 12, 2012; revised Sept. 13, 2012; accepted Sept. 13, 2012.

Author contributions: E.S. designed research; K.R.M. performed research; E.S. contributed unpublished reagents/ analytic tools; K.R.M. analyzed data; K.R.M. and E.S. wrote the paper.

This work was supported by predoctoral programs in the neurosciences (T32 NS41228) and developmental biology (T32 HD007180) to K.R.M., a Basil 0'Connor Award from the March of Dimes, the Klingenstein Award, an NSF-Career Award, the Kavli Initiative at Yale, and Yale University bridge funding provided by the Provost to E.S. We thank Drs. Anne Williamson, David Wells, and Scott Holley for use of their equipment and Drs. Koleske, Kochanek, and Zhong for helpful discussions and experimental advice. We also thank Drs. Biederer, De Camilli, and Zhong for providing protocols and reagents. We thank Dr. Nelson for assistance with FACS and Dr. Burgess for the DSCAM del17 mice.

The authors declare no competing financial interests.

Correspondence should be addressed to Elke Stein, Yale University, Department of Molecular, Cellular and Developmental Biology, Cell Biology and Interdisciplinary Neuroscience Program, 219 Prospect Street, KBT-232, New Haven, CT 06511. E-mail: elke.stein@yale.edu.

DOI:10.1523/JNEUROSCI.2811-12.2012

Copyright $\odot 2012$ the authors $\quad 0270-6474 / 12 / 3216637-14 \$ 15.00 / 0$ ford et al., 2002; Horch et al., 1999), the molecular mechanisms orchestrating cortical dendrite development and circuit formation are only at the verge of being elucidated.

Significant insights into the mechanisms that contribute to dendrite development have come from studies of the Down syndrome cell adhesion molecule (DSCAM). DSCAM is a homophilic cell adhesion molecule (Yamakawa et al., 1998; Agarwala et al., 2000) as well as a netrin-1 receptor (Ly et al., 2008; Andrews et al., 2008) and has been implicated in the development of the nervous system (Schmucker and Chen, 2009). In Drosophila, DSCAM, for example, regulates dendrite patterning (Zhu et al., 2006), controls dendrite self-avoidance (Matthews et al., 2007; Soba et al., 2007), and regulates postsynaptic specificity of multiple-contact synapses (Millard et al., 2010). Furthermore, in Aplysia DSCAM mediates the remodeling of glutamate receptors during de novo and learning-related synaptogenesis (Li et al., 2009). Similarly in vertebrates, DSCAM directs lamina-specific synaptic connections in the avian retina (Yamagata and Sanes, 2008), whereas in mice, DSCAM governs neurite arborization, mosaic tiling, and dendrite self-avoidance in the retina of mice (Fuerst et al., 2008, 2009).

Interestingly, upregulation of DSCAM has recently been associated with altered circuit formation in two independent mouse models of Down syndrome (DS), Ts1Cje and Ts1Rh (Olson et al., 2004; Sago et al., 1998). Hippocampal neurons derived from Ts1Cje mice show a loss in NMDA-mediated regulation of DSCAM in local mRNA translation, which leads to alterations in dendrite morphology and synaptic plasticity (Alves-Sampaio et al., 2010), whereas the analysis of Ts1Rhr mice suggests that DSCAM is a regulator of eye-specific segregation of retinogeniculate projection (Blank et al., 2011). 
While DSCAM mRNA has been reported to localize to the developing cortex (Barlow et al., 2002), its precise contribution to cortical wiring remains unclear. Here, we analyze DSCAM mutant mice for defects in dendrite arborization and spine morphogenesis in layer $\mathrm{V}$ cortical pyramidal neurons. We provide evidence that $D S C A M^{\text {dell7 }}$ mice have reduced cortical thickness and impairments in pyramidal neuron dendrite arborization. We also show that $D S C A M^{\text {dell7 }}$ mice exhibit alterations in spine morphogenesis in early development and adulthood, including increases in spine density and reductions in spine size. These data suggest that $D S C A M^{\text {dell7 }}$ mice are vulnerable to the formation of abnormal cortical circuits and that DSCAM is necessary for development of cortical dendrites and spines.

\section{Materials and Methods}

Mouse lines and breeding. Mice were housed and handled according to protocols approved by the Institutional Animal Care and Use Committee at Yale University. DSCAM dell7 mutant mice were kindly obtained from Robert Burgess (Jackson Laboratories) and maintained in a predominantly DBA2 background. Mice expressing YFP in layer V pyramidal cells of motor and somatosensory cortex [B6.Cg-Tg(Thy1-YFP-H)2Jrs/J] (Feng et al., 2000) were obtained from Jackson laboratories and crossed with DSCAM ${ }^{\text {dell7 }}$ mice to obtain DSCAM ${ }^{\text {del17 }}$-Thy1-YFPH mice. Genotyping for $D S C A M^{\text {dell }}$ mice was performed as described in the study by Fuerst et al. (2008). Male and female mice were used in all experiments.

Nissl staining. For representative Nissl-stained images, postnatal mice ( $\mathrm{P} 1, \mathrm{P} 10, \mathrm{P} 21$, or $\mathrm{P} 42)$ were anesthetized and perfused with $4 \%$ paraformaldehyde (PFA)/PBS. Brains were dissected and postfixed overnight in $4 \% \mathrm{PFA} / \mathrm{PBS}$ at $4^{\circ} \mathrm{C}$. The following day brains were washed with PBS and $50-\mu \mathrm{m}$-thick sections were cut coronal using a vibratome and collected on glass slides. Sections were stained with cresyl violet, dehydrated, cleared, and coverslipped with Cytoseal 60 (Richard-Allen Scientific). Vibratome sections were imaged under $1 \times, 4 \times$, or $10 \times$ magnification using a Nikon Eclipse light microscope and captured using Spot software.

Immunoblotting. Tissue samples were lysed with WG buffer (Stein et al., 1996) and protein concentrations were determined using the bicinchronic acid assay (Pierce Biotechnology). Crude extracts (4 mg) were bound to ConA Sepharose beads (GE Healthcare) and eluates were separated on 8\% SDS-PAGE, blotted to PVDF membrane (Millipore), and probed with antibodies specific to DSCAM (Ly et al., 2008), actin (Sigma), PSD-95 (NeuroMab), SynCAMs1-3 (gift from the Biederer laboratory, Yale University, New Haven, CT), GDI (gift from De Camilli laboratory, Yale School of Medicine, New Haven, CT), incubated with the respective secondary antibodies, and visualized using the chemiluminescent detection reagents, ECL (GE Healthcare).

Volumetric analysis. Nissl-stained vibratome sections in the coronal plane were prepared as described above from three wild-type (wt) and three DSCAM $M^{\text {del } 17}$ mutant brains and imaged at $1 \times$ using a Nikon Eclipse light microscope as described above. Individual images from each brain were stacked and aligned using ImageJ. The resulting stacks were then subjected to volume reconstruction using Imaris software (Bitplane Scientific Software). The hippocampus was used as a landmark to define regions of interest. Anterior cortical volume was defined as the region starting $1200 \mu \mathrm{m}$ before to the beginning of the hippocampus. Posterior cortical volume was defined as the cortical region starting $850 \mu \mathrm{m}$ before the start of the hippocampus. Thalamic volume was defined as the region starting $500 \mu \mathrm{m}$ before to the beginning of the hippocampus. Hippocampal volume was defined as the region spanning the first $850 \mu \mathrm{m}$ of the hippocampus.

In situ hybridization. Brains were isolated from embryos (E16.5, E18.5) or postnatal mice (P3, P10, P14), washed with RNase-free PBS, and fixed in $4 \%$ PFA overnight. Brains were washed with PBS, cryoprotected in $30 \%$ sucrose/PBS, embedded in OCT (TissueTek), and cryosectioned (Leica Microsystems). Tissue sections were processed for in situ hybridization as described previously (Serafini et al., 1994). ${ }^{35}$ S-labeled antisense and sense riboprobes were generated from the cytoplasmic domain of mouse DSCAM (Accession: NM_031174) or mouse Fezf2 (Accession: NM_080433).
Enzymatic dissociation and FACS purification of YFP neurons. Brains from adult transgenic Thy1-EYFP-H mice were dissected and cut in the coronal plane using a razor blade. Cortices were dissected and dissociated using the NeuroCult Enzymatic Dissociation Kit (Stemcell Technologies) according to the manufacturer's protocol. Cells were filtered through a $40 \mu \mathrm{m}$ mesh and resuspended in PBS with calcium and magnesium supplemented with $4 \%$ fetal calf serum. Cells were incubated with propidium iodide (PI) (1:2000) and sorted by FACS (BD Biosciences) for fluorescein-5-isothiocyanate (FITC for EYFP) and for Allophycocyanin (APC for PI) signals, respectively. Cortical cells derived from wt mice were used to calibrate the FITC and APC signals. Cells with high FITC signals (FITC $>4 \times 10^{3}$ ) and negative PI signals were selected. As a control, cells with low FITC signals and negative PI signals were separately selected. Cells were sorted directly into lysis buffer for RNA isolation. Approximately $5 \times 10^{5}$ cells were obtained for both cell populations.

RNA isolation and RT-PCR. RNA extraction was performed using the RNeasy Mini Kit with a DNase I digestion (Qiagen) according to manufacturer's protocol. For all reverse-transcriptase PCRs (RT)-PCRs, $10 \mathrm{ng}$ of RNA was used as the template. RT-PCR was performed on RNA isolated from YFP+/PI- and YFP-/PI- neurons using the Superscript One-Step RT-PCR with Platinum Taq (Invitrogen) and primers for YFP (5'-primer: 5'-TTGAATTCGCCACCATGGTGAGC-3' and $3^{\prime}$-primer: $5^{\prime}$-TTGAATTC TTACTTGTACAGCTCGTCC-3'), Bcl11b (5' - primer:5'-GCGAGCGGGG GCAGCACAC-3' and $3^{\prime}$-primer: $5^{\prime}$-TGGCGAAGGTTG GCGATGGTCA$\left.3^{\prime}\right)$, or the first three fibronectin domains of DSCAM spanning exons 15-18 (5'-primer: 5'-AAGAACCGGATTGGCAAGAGTGAG-3' and 3'-primer: 5'-GTGAGGTTGCTATGG CTTGGACAT-3').

Subcellular fractionation. Subcellular fractionation was performed according to methods previously described by Jones and Matus, 1974. Briefly, four adult mice were anesthetized and forebrains were removed and homogenized in $320 \mathrm{~mm}$ sucrose/10 mM HEPES, pH 7.4. Homogenates were centrifuged (Beckman-Coulter Avanti J-20 XP; JLA 16.25 rotor), subjected to hypotonic lysis, and subjected to ultracentrifugation (Beckman-Coulter L8-70 M; Ti70 rotor) to isolate multiple brain fractions including crude homogenate $(\mathrm{CH})$, crude lysate $(\mathrm{S} 1)$, synaptosomal supernatant (S2), washed synaptosomes (P2'), lysis supernatant (LS1), and synaptosomal membranes (LP1). LP1 fractions were subjected to a secondary ultracentrifugation step in a sucrose gradient (SW40 rotor) to obtain myelin, synaptic plasma membrane, and mitochondrial fractions.

Cortical thickness quantification. P1, P10, P17, P21, or P42 brains were removed, fixed overnight in $4 \%$ PFA, cryopreserved, and $14 \mu \mathrm{m}$ cryosectioned. Sections were stained with cresyl violet, dehydrated, cleared, and coverslipped with Cytoseal 60. Corresponding anterior and posterior regions were selected for imaging at $5 \times$ or $10 \times$ using a Zeiss Axioplan2 light microscope connected to a monochrome digital camera and AxioVision3.1 software. Given gross differences in size and shape between wt and mutant brains, the hippocampus was used as a common landmark to determine corresponding anterior and posterior regions. Measurements of cortical thickness were recorded on sections spanning from $\sim 500 \mu \mathrm{m}$ anterior to $\sim 500 \mu \mathrm{m}$ posterior to the start of the hippocampus and statistically analyzed using unpaired Student's $t$ test.

Immunofluorescence and analysis of laminar thickness. For all immunohistochemical procedures, mice were anesthetized and perfused with $4 \%$ PFA/PBS. Brains were dissected and postfixed in $4 \%$ PFA/PBS at $4{ }^{\circ} \mathrm{C}$ overnight, washed three times with PBS, cryoprotected in 30\% sucrose/ PBS, and embedded coronally in OCT. Cryosections were cut at $14 \mu \mathrm{m}$ using a cryostat. Sections were washed twice with PBS, permeabilized for 20 min with PBS/0.1\% Triton X-100 (PBST), blocked for at least $1 \mathrm{~h}$ at room temperature (RT) with heat-inactivated goat serum (5\%) and horse serum (5\%) in PBS-T, and incubated in anti-Tbr1 1:200 (AbCam) and anti-Bcl11b 1:200 (Santa Cruz Biotechnology) or anti-Cutl1 1:1000 (Santa Cruz Biotechnology) and anti-Bcll1b overnight at RT. Sections were then washed with PBS, incubated with DAPI 1:1000, anti-rat Alexa 488 1:000, anti-rabbit Alexa555 1:1000 (Jackson Research) for $1 \mathrm{~h}$ at RT in blocking solution, washed with PBS, and mounted with Fluoromount-G (Southern Biotech). Images were taken at $10 \times$ using a Zeiss Axioplan2 light microscope connected to a monochrome digital camera and AxioVision3.1 software. Measurements of 
laminar thickness were recorded from $\sim 300 \mu \mathrm{m}$ anterior to $\sim 300 \mu \mathrm{m}$ posterior of the hippocampus and analyzed statistically by unpaired Student's $t$ test.

BrdU staining and quantifications. Timed pregnant mice were intraperitoneally injected with $2.5 \mathrm{mg}$ of BrdU (Sigma) in PBS at embryonic day 16.5 (E16.5). After $30 \mathrm{~min}$, mice were euthanized and embryonic brains were collected. Brains were fixed with $4 \%$ PFA/PBS overnight. Cryosections $(14 \mu \mathrm{m})$ were washed with PBS, permeabilized with 13 $\mu \mathrm{g} / \mathrm{ml}$ Proteinase K (Roche) for $5 \mathrm{~min}$, incubated with $3 \%$ hydrogen peroxide (Sigma) for $15 \mathrm{~min}$ at RT, and treated with $2 \mathrm{~m}$ hydrochloric acid for $45 \mathrm{~min}$ at $37^{\circ} \mathrm{C}$. Sections were blocked for at least $1 \mathrm{~h}$ at RT in blocking solution (50 mm TrisCl pH 8.0, $0.1 \mathrm{~m} \mathrm{NaCl}, 0.1 \%$ Triton X-100, $3 \%$ HINGS, $0.1 \%$ BSA) and incubated with anti-BrdU 1:300 (AbCam) in blocking solution overnight at RT. Sections were washed three times with PBS, incubated in biotin-conjugated anti-rat secondary 1:200 (Jackson ImmunoResearch) in blocking solution for $90 \mathrm{~min}$ at RT, followed by three washes with PBS, and treated with Vectastain Elite ABC Kit (Vector Laboratories) for $1 \mathrm{~h}$ at RT. Sections were then washed with PBS, incubated in $50 \mathrm{~mm}$ Tris- $\mathrm{HCl} \mathrm{pH} \mathrm{7.2,} \mathrm{and} \mathrm{immunoreactivity} \mathrm{detected} \mathrm{with}$ diaminobenzidine (Sigma). The reaction was stopped, sections were cleared and coverslipped with Cytoseal 60 and imaged at $20 \times$ magnification using a Nikon Eclipse light microscope connected to colored digital camera and Spot software. Quantification was performed as described by Petersen et al., 2004. Briefly, to count the number of BrdU-labeled cells after a 30 min pulse, four images of different but corresponding regions of dorsal forebrain were taken from each embryo ( $n=3$ per genotype). All BrdU-labeled cells within a box covering the thickness of the ventricular and subventricular zone in E16.5 embryos were counted (two such boxes per image). The total number of cells in each image were divided by two, and defined as the average number of cells per unit (one box).

TUNEL staining and quantification. P1 brain sections collected for laminar studies (see above) were also examined for levels of apoptosis using the TUNEL method (ApopTag Red Is Situ Apoptosis Detection Kit, Millipore). Sections were stained according to manufacturer's protocol and were counterstained with DAPI at 1:1000 before mounting. E12.5 cortex from $A C B D 3^{M y r}$ mutant mice (Zhou et al., 2007) were used as a positive control. Fluorescent micrographs were taken using a Zeiss Axioplan2 light microscope and analyzed using AxioVision3.1 software. To quantify TUNEL staining, all labeled cells in a forebrain sections were counted (6 sections per brain; 3 brains per genotype).

Immunostaining of DSCAM $M^{\text {dell7 }}$-Thy1-YFP-H slices. Wt and mutant $D_{S C A M}{ }^{\text {dell7 }}$-Thy1-YFPH mice were deeply anesthetized and transcardially perfused with $4 \%$ PFA/PBS. Brains were dissected and postfixed overnight in $4 \% \mathrm{PFA} / \mathrm{PBS}$ at $4^{\circ} \mathrm{C}$ and washed with PBS. Brains were then cut into $50-\mu \mathrm{m}$-thick coronal sections with a vibratome and immunostained in 24-well plates with a GFP antibody to visualize the YFPpositive dendritic spines. Briefly, slices were permeabilized with $0.3 \%$ PBST for $30 \mathrm{~min}$, blocked in 5\% heat-inactivated horse serum/PBST for an hour at RT, and incubated in anti-GFP 1:1000 (Invitrogen) in block overnight at $4^{\circ} \mathrm{C}$. Slices were washed and incubated in anti-rabbit Alexa 488/PBST (Jackson ImmunoResearch) for $1 \mathrm{~h}$ at $\mathrm{RT}$ and processed as above for confocal microscopy.

Golgi staining and morphometric analysis. Golgi-Cox staining of postnatal brains was performed using the FD Rapid GolgiStain Kit (FD Neurotechnologies). Brains were obtained from postnatal mice at P10, P17, and P42 and impregnated with Golgi-Cox solution at RT in the dark for 3,4 , and $5 \mathrm{~d}$, respectively. At least three brains per genotype per age group were impregnated, followed by an incubation in $30 \%$ sucrose for $48 \mathrm{~h}$ at $4^{\circ} \mathrm{C}$ and embedded coronally in OCT. Brain hemispheres were then sectioned at $150 \mu \mathrm{m}$ with a vibratome and stained according to manufacturer's protocol. Individual layer $\mathrm{V}$ neurons in motor and somatosensory cortex were traced with the observer blinded to genotype under $100 \times$ magnification using a light microscope, and tracings were reconstructed using Neurolucida software (MicroBrightField). For the analysis, the total length of apical branches, the number of apical branchpoints, the mean apical branch length, and the total length of basal dendrites were calculated using NeuroExplorer software (MicroBrightField) and analyzed statistically by unpaired Student's $t$ test. For the Sholl analysis, concentric three-dimensional shells of increasing diameter are centered around the cell body; the number of intersections of the dendrite arbor with a given shell was plotted versus the distance.

Preparation, transfection, and analysis of primary cortical cultures. E16.5 embryos were isolated from $D S C A M^{\text {del17 }}$ heterozygous timed-pregnant females, and cortices were dissected from individual embryos in L15 medium. Dissociation of cortices was performed as described previously (Polleux and Ghosh, 2002). Briefly, cortices were washed with sterile PBS and incubated for $40 \mathrm{~min}$ at $37^{\circ} \mathrm{C}$ in dissociation medium containing 10 $\mathrm{U} / \mathrm{ml}$ of papain (Worthington). After quenching the enzymatic reaction with trypsin inhibitor (Sigma) and BSA, cortices were gently triturated in serum-free medium containing glutamate (Invitrogen). Neurons from each embryo were plated in separate wells on dishes coated with poly-Llysine (Sigma) and laminin (Invitrogen) and cultured for $3 \mathrm{~d}$ in vitro in Neurobasal medium containing B27 supplement (Invitrogen) and antibiotics. On day 2, neurons were transfected with pCAGGs-EGFP using the calcium-phosphate method (Roche). Neurons were incubated with 2 $\mu \mathrm{g}$ of pCAGGs-EGFP, $2 \times$ HBS, and calcium chloride in DMEM for 30 min at $37^{\circ} \mathrm{C}$. After washing with DMEM, the medium was replaced and neurons were cultured for an additional $24 \mathrm{~h}$. On day 3, neurons were fixed with $4 \%$ formaldehyde $/ 30 \%$ sucrose for $10 \mathrm{~min}$ at RT, permeabilized with $0.3 \%$ Triton in PBS for 10 min, blocked for $1 \mathrm{~h}$ at RT with heat inactivated goat $(5 \%)$ and horse serum $(5 \%)$ in PBST, and incubated in anti-GFP (Invitrogen) overnight at $4^{\circ} \mathrm{C}$. Neurons were washed three times with PBS, incubated with anti-rabbit Alexa488 1:1000 (Jackson ImmunoResearch) for $1 \mathrm{~h}$ at RT, and washed as above. Wt and mutant pyramidal neurons were imaged using a Zeiss Axiovert200 light microscope using AxioVision3.1 software. Pyramidal neurons were identified by cell morphology. Lengths and numbers of primary, secondary, and tertiary dendrite branches were quantified using ImageJ software. Results were derived from two independent litters: wt 4 brains, 88 neurons; DSCAM ${ }^{\text {del17 }}$ mutant 5 brains, 96 neurons.

Imaging and quantification of dendritic spines. YFP-labeled layer V pyramidal neurons in motor and somatosensory cortex were imaged in coronal sections by confocal microscopy using a Zeiss confocal LSM 510 system. The system had an argon laser with an exciting wavelength for $488 \lambda$. The morphology of YFP-labeled apical branches of pyramidal neuron were studied using a $63 \times$ objective $(63 \times / 1.4$ oil $)$; a $3 \times$ digital zoom; optical sections were scanned at increments of 0.6-0.7 $\mu \mathrm{m}$ and each optical slice has a four-line average; image size of $512 \times 512$ pixels. Each image was saved as a stack of individual optical sections and a $Z$-projection. For each age (P15, P21, and P42) and genotype, 60 neurons ( 3 brains per genotype; 20 neurons per brain) and two YFP-labeled apical branches per neuron were imaged. For each branch the spine density (spines per micrometer) was quantified by measuring the length of a branch segment $(20-45 \mu \mathrm{m})$, counting the number of spines along the defined segment, and dividing the total number of spines by the measured length. For each neuron, the final recorded spine density was the average of the two analyzed branches, similar as established by Tran et al., 2009. Quantification of spine morphology was performed using ImageJ by measuring the height of the spine and the width of the spine head. For each age, a total of 120 branch segments were analyzed. Spine height and width measurements were converted from pixels to micrometers and then binned by size.

Statistical analysis. Quantitative data are presented as means and SEM. The significance for comparisons was calculated using unpaired Student's $t$ test (GraphPad Prism version 4.0c, GraphPad Software).

\section{Results}

\section{Gross changes in brain size and shape in $D_{S C A M}{ }^{\text {del17 }}$ mutants} While DSCAM ${ }^{\text {dell7 }}$ mutants have been reported to display overt neurological phenotypes in the retina (Fuerst et al., 2008) and its projections to the thalamus (Blank et al., 2011), phenotypes in other regions of the CNS have not been carefully examined. To investigate a potential role for DSCAM in pyramidal neuron morphogenesis and cortical circuit development, we first sought to thoroughly characterize the gross morphology of DSCAM del17 mutant brains. 

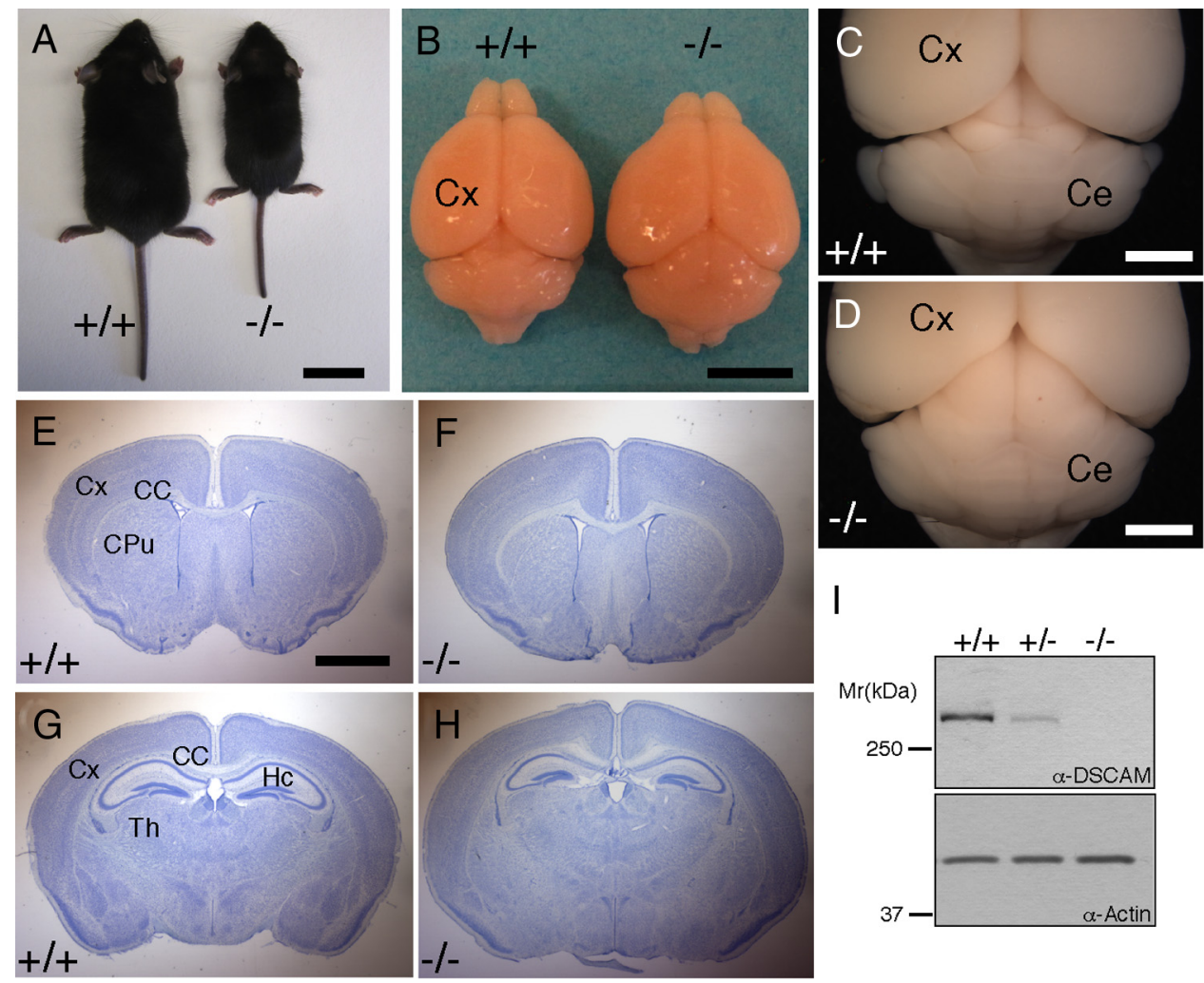

$\mathrm{J}$
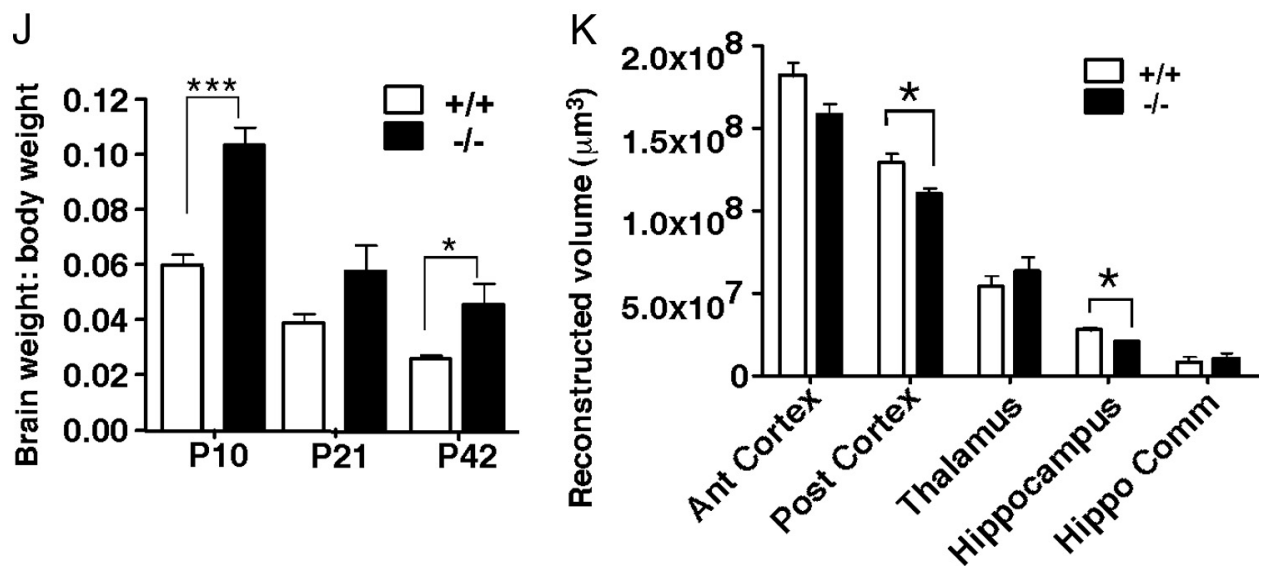

Figure 1. DSCAM del17 mutants exhibit abnormal gross brain morphology. $A-I$, At postnatal day $P 21, D S C A M^{\text {del17 }}$ mutant mice are smaller in body size compared with their wt littermates $(A)$. The brains of $D S C A M^{d e l 17}$ mutants are increased in length and decreased in width $(\boldsymbol{B})$, have an enlarged tectum and abnormally shaped cerebellum $(\boldsymbol{B}, \boldsymbol{D})$ compared with wt littermates, $\boldsymbol{B}$ and $\boldsymbol{C}$. $\boldsymbol{E}-\boldsymbol{H}$, Nissl-stained coronal sections $(50 \mu \mathrm{m})$ of corresponding regions in wt at different levels, $\boldsymbol{E}$ and $\boldsymbol{G}$, and mutant brains, $\boldsymbol{F}$ and $\boldsymbol{H}$. In DSCAM del17 mice the total brain size is increased whereas the hippocampal $(\mathrm{HC})$ size is decreased $(\boldsymbol{H})$, compared with wt $(\mathbf{G})$. $\boldsymbol{I}$, Protein expression in tissue extracts derived from the cortex of wt, DSCAMdel17 heterozygote, or mutant mice. DSCAM protein expression accessed by Western blotting in cortical extracts derived from P21 brains of the indicated genotype. $\alpha$-Actin was used as a loading control. J, Ratio of brain to body weight at P10, P21,

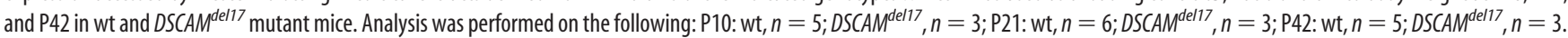
$\boldsymbol{K}$, Volume reconstruction of defined areas of P21 anterior cortex (Ant cortex), posterior cortex (Post cortex), thalamus (Th), hippocampus (Hippo), and the hippocampal commissure (Hippo Comm). Brains for each genotype were evaluated: $n=3$. CPu, Caudate-putamen; Th, thalamus. Scale bars: $2 \mathrm{~cm}(\boldsymbol{A}), 500 \mathrm{~mm}(\boldsymbol{B}), 2 \mathrm{~mm}(\boldsymbol{C}-\boldsymbol{H})$. Mean $\pm \mathrm{SE} ;{ }^{*} p<0.05$, ${ }^{* * *} p<0.001 \mathrm{compared}$ with wt (Student's $t$ test).

Wt and $D S C A M^{\text {dell7 }}$ mutants were indistinguishable at birth, but as postnatal development progressed, mutants were easily identified by a decrease in body size (Fig. $1 A$ ). At P10, mutants were significantly smaller in size compared with wt littermates $(3.851 \pm 0.2358$ and $6.184 \pm 0.2879 \mathrm{~g}$, respectively; $p=0.0015$; Student's $t$ test). This decrease in body size persisted into adulthood as P42 mutants were still smaller compared with wt littermates $(13.03 \pm 2.489$ and $20.39 \pm 1.342 \mathrm{~g}$, respectively; $p=0.0279$; Student's $t$ test). In addition to changes in body size, $D S C A M^{\text {dell7 }} \mathrm{mu}-$ tants displayed gross alterations in brain size and shape compared with wt littermates, thus (Fig. $1 B$ ) mutant versus wt brains were significantly larger in size by P21 ( $0.5249 \pm 0.02066$ and $0.4292 \pm$ $0.00621 \mathrm{~g}$, respectively; $p=0.0006$; Student's $t$ test). Given that mutants displayed a decrease in body size accompanied by an increase in brain size, ratios of brain to body weight were significantly larger for mutant mice compared with wt mice (Fig. 1J; for P10: $0.1041 \pm 0.006$ and $0.0597 \pm 0.00369$, respectively; $p=$ 0.0005 ; for P42: $0.0457 \pm 0.0074$ and $0.02602 \pm 0.00135$, respectively; $p=0.0135$; Student's $t$ test). In addition to being larger in size, mutant brains were shorter in length, wider, and had en- 

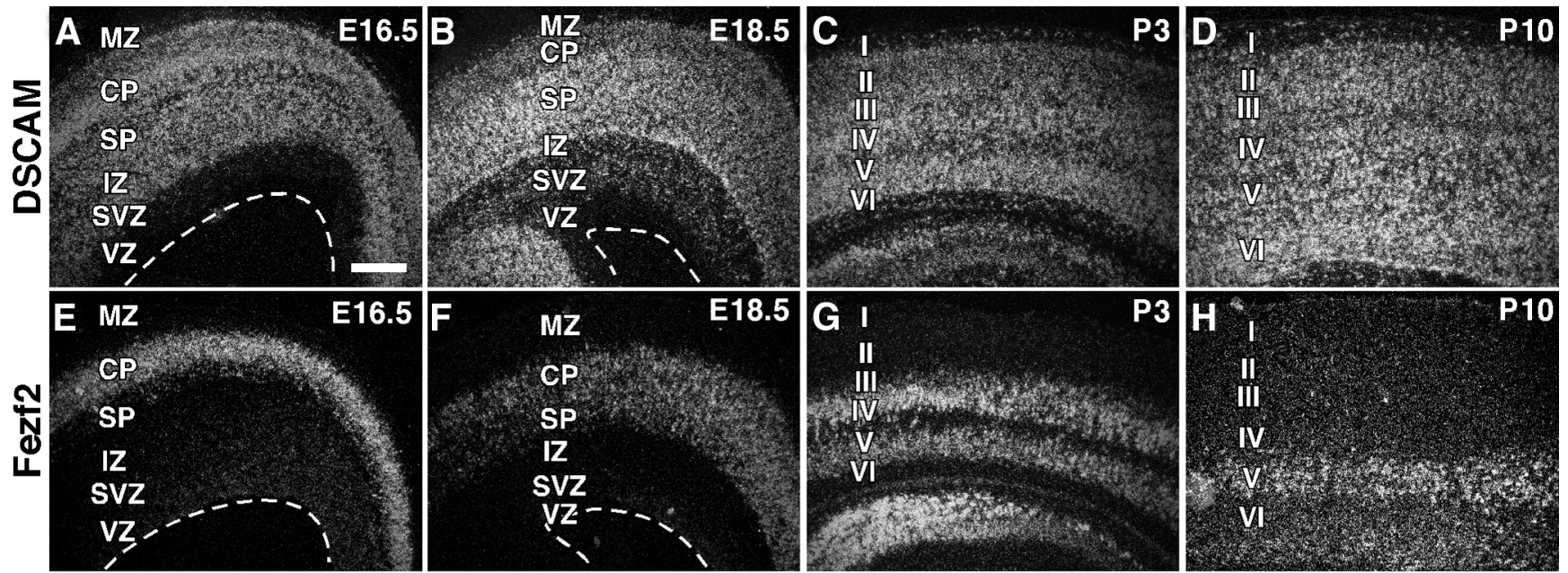

I

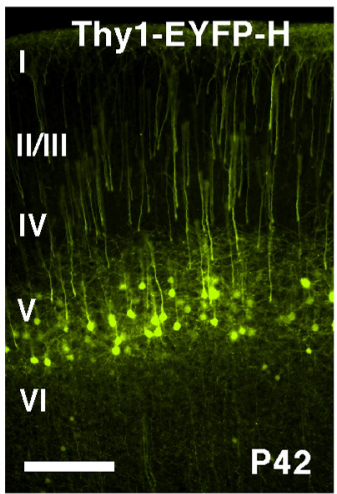

K
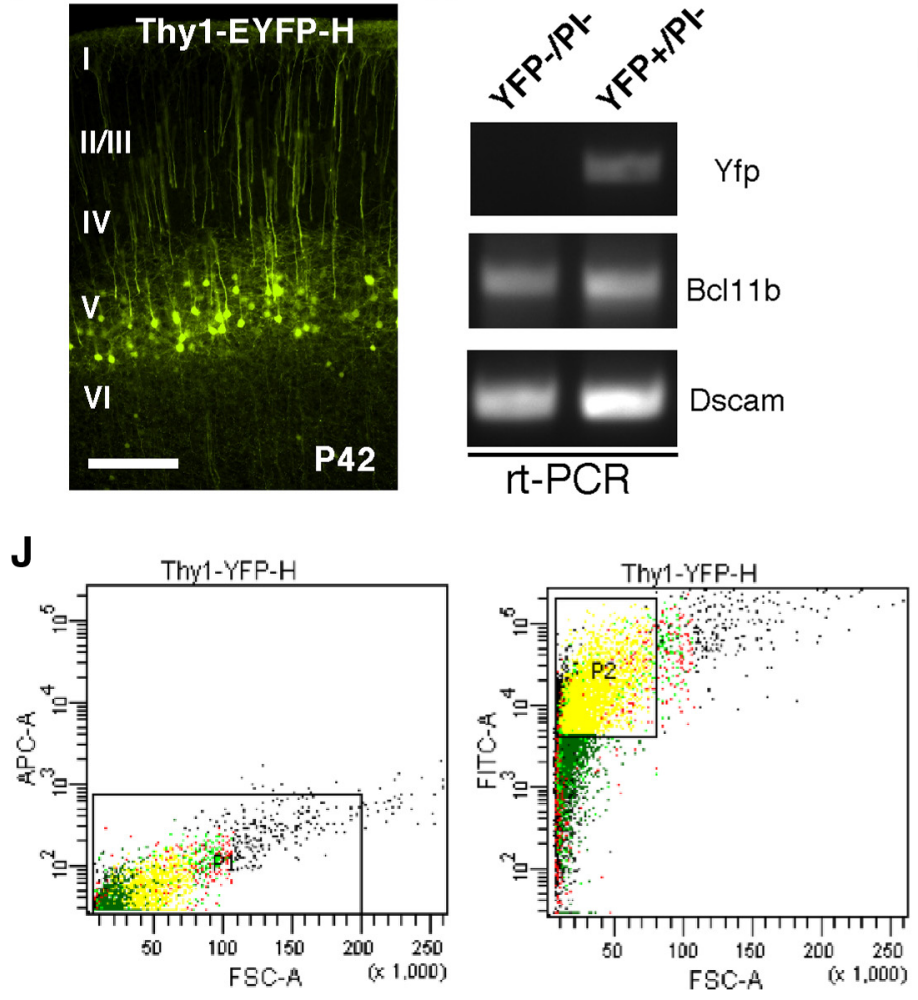
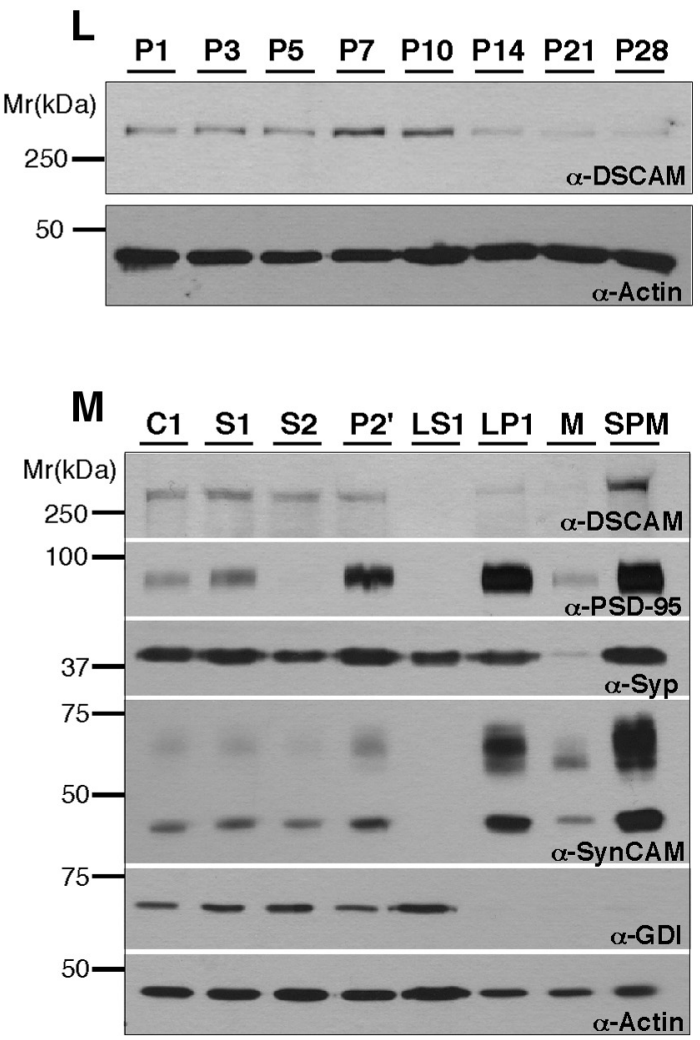

Figure 2. DSCAM expression during cortical development. $\boldsymbol{A}-\boldsymbol{H}$, Coronal sections of $\mathrm{E} 16.5(\boldsymbol{A}, \boldsymbol{E}), \mathrm{E} 18.5(\boldsymbol{B}, \boldsymbol{F}), \boldsymbol{P 3}(\boldsymbol{C}, \boldsymbol{G})$, and $\mathrm{P} 10(\boldsymbol{D}, \boldsymbol{H})$ cortex hybridized with radioactive RNA probes against DSCAM $(\boldsymbol{A}-\boldsymbol{D})$ and Fezf2 $(\boldsymbol{E}-\boldsymbol{H})$, a transcription factor expressed by corticospinal motor neurons that will occupy layer V. DSCAM mRNA is ubiquitously expressed throughout the cortical plate during embryonic and postnatal development $(\boldsymbol{A}-\boldsymbol{D})$ and is particularly upregulated in developing corticospinal motor neurons. $\boldsymbol{I}$, Fluorescent image showing Thy1-EYFP-H expression in layer V pyramidal neurons at P42.J, FACS of YFP (FITC) +/PI (APC) - pyramidal neurons from Thy1-EYFP-H adult cortices. Left and right, sorting of PI and YFP, respectively. Cells within box P1 are PI-, and cells within box P2 are PI - /YFP +. K, RT-PCR for DSCAM, BCl11b, and YFP using samples prepared from YFP - /PI - and YFP +/PI - sorted neurons. L, Assessment of DSCAM protein levels in cortical tissues derived from P1-P28 using Western blot analysis. DSCAM protein levels peak between P7 and P10. Actin immunoreactivity was used as a loading control. $\boldsymbol{M}$, Subcellular expression of DSCAM, PSD-95, synaptophysin, SynCAM, GDI, and actin in multiple brain fractions including $\mathrm{CH}, \mathrm{S1}, \mathrm{S2}, \mathrm{P2}{ }^{\prime}$, LS1, LP1, M, and SPM. DSCAM is enriched in SPM fraction. Scale bar: (in $\boldsymbol{A}$ ) $\boldsymbol{A}-\boldsymbol{H}$, $100 \mu \mathrm{mm}$.

larged midbrains (Fig. 1C,D). Nissl staining of P21 coronal sections revealed no gross disorganization of the cortex, caudate/ putamen, corpus callosum (Fig. $1 E, F$ ), or hippocampus (Fig. $1 G, H)$. Quantification of a defined region of anterior cortex revealed no significant changes in cortical volume between mutant and wt brains (Fig. $1 K$ ). However, mutant brains did show a significant decrease in the volume of a defined region of posterior cortex compared with wt brains (Fig. $1 K ; 1.10 \times 10^{8} \pm 3.51 \times$ $10^{6}$ and $1.29 \times 10^{8} \pm 5.83 \times 10^{6} \mu \mathrm{m}^{3}$, respectively; $p=0.0472$; Student's $t$ test). Furthermore, mutant brains displayed a signif- icant decrease in the volume of a defined region of hippocampus compared with wt brains (Fig. $1 K ; 2.09 \times 10^{7} \pm 772079$ and $2.80 \times 10^{7} \pm 1.37 \times 10^{6} \mu \mathrm{m}^{3}$, respectively; $p=0.0106$; Student's $t$ test). There were no significant changes in the volume of the hippocampal commissure or a defined region of thalamus between wt and mutant brains (Fig. $1 K$ ).

To evaluate whether the DSCAM ${ }^{\text {dell7 }}$ mutation resulted in elimination of all DSCAM protein from the cortex, we used a polyclonal antiserum generated against the last 100 aa of the DSCAM intracellular domain (Ly et al., 2008) and examined the 

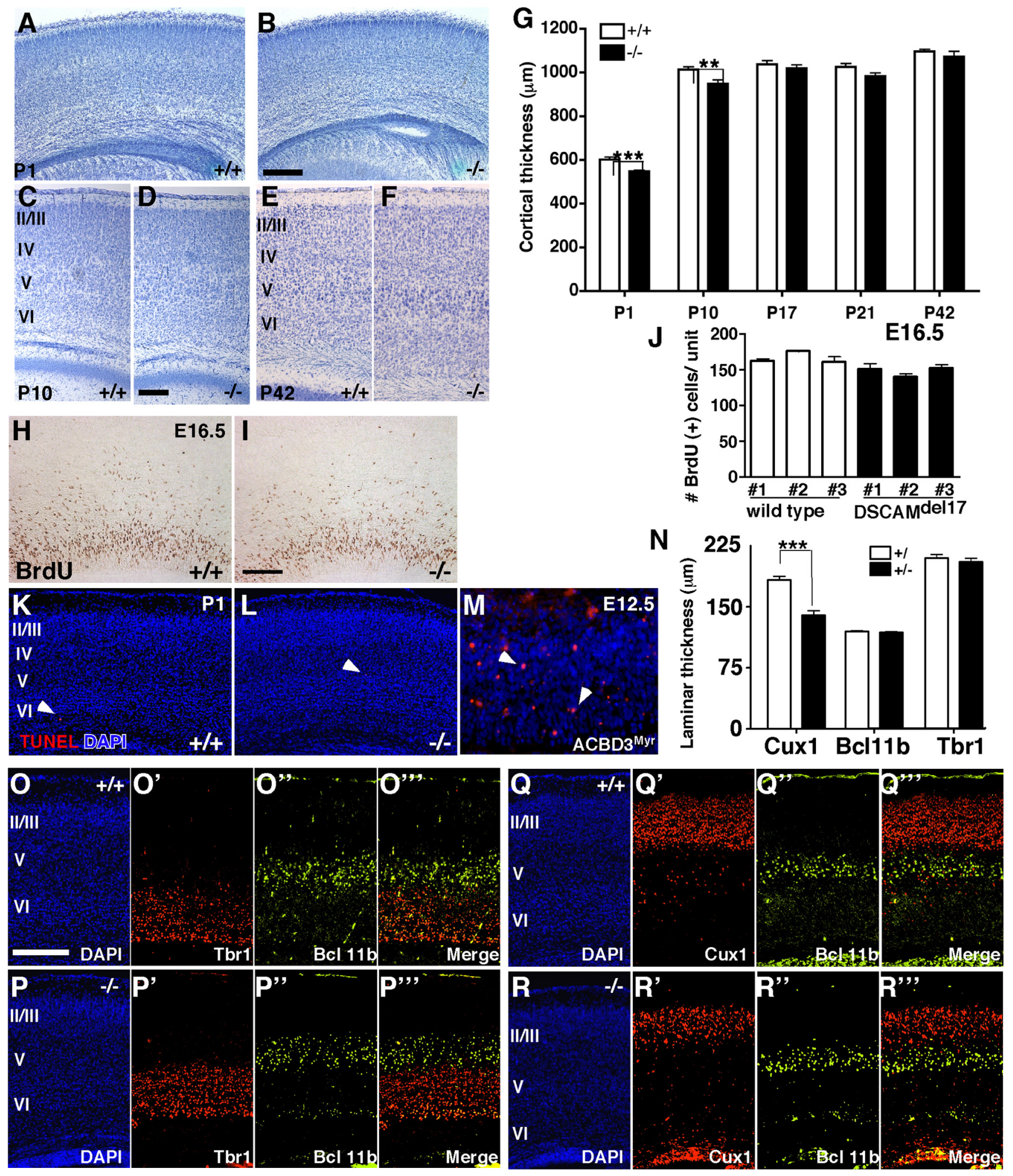

Figure 3. Lack of DSCAM in DSCAM del17 mutant causes changes in cortical thickness and lamination in early postnatal animals. $A-\boldsymbol{F}$, Nissl-stained coronal brain sections $(50 \mu \mathrm{m})$ from $P 1(\boldsymbol{A}, \boldsymbol{B})$, P10 $(\boldsymbol{C}, \boldsymbol{D})$, and P42 $(\boldsymbol{E}, \boldsymbol{F})$ wt $(\boldsymbol{A}, \boldsymbol{C}, \boldsymbol{E})$ and $D S C A M^{\text {del } 17}$ mutant $(\boldsymbol{B}, \boldsymbol{D}, \boldsymbol{F})$ littermates. Sections of the cortex above the hippocampus with the pial surface oriented at the top. $\boldsymbol{G}$, Quantification of mean cortical thickness at P1, P10, P17, P21, and P42 in wt and DSCAM del17 mutant littermates. Analysis was performed on the following: P1: wt, $n=4$ brains, 69 sections; DSCAM del17 mutant, $n=5$ brains, 94 sections; P10: wt, $n=6$ brains, 96 sections; DSCAM ${ }^{\text {del } 17}, n=4$ brains, 59 sections; P17: wt, $n=3$ brains, 57 sections; DSCAM ${ }^{\text {del } 17}, n=3$ brains, 51 sections; $P 21:$ wt, $n=3$ brains, 50 sections; DSCAM del17,$n=3$ brains, 52 sections; P42: wt, $n=4$ brains, 54 sections; DSCAM del17,$n=4$ brains, 55 sections. $\boldsymbol{H}-\boldsymbol{I}$, Representative coronal sections derived from E16.5 wt (H) and DSCAM ${ }^{\text {del } 17}$ mutant $(I)$ cortex after a $30 \mathrm{~min}$ BrdU pulse. J, Quantitative analysis of BrdU-labeled S-phase cells in the developing neocortex of E16.5 embryos after a 30 min pulse. Each column represents the average number of a single embryo. Error bars show SE. $\boldsymbol{K}-\boldsymbol{L}$, Representative coronal sections of TUNEL staining in wt $(\boldsymbol{K})$ and $D S C A M^{\text {del17 }}$ mutant $(\boldsymbol{L}) P 1$ cortices and in $A C B D 3^{M y r}$ E12.5 cortex representing as a positive control $(\boldsymbol{M})$. $\boldsymbol{N}$, Quantitative analysis of cortical lamination at P1. While the thickness of upper cortical layers II/III (Cutl1 + ) is reduced in DSCAM ${ }^{\text {del17 }}$ mutants, layer V and VI cortical lamination (BCl11b + and Tbr1+, respectively) remains intact. Analysis of laminar thickness was performed on the following: Cut11: wt, $n=3$ brains, 42 sections; DSCAM del17 mutant, $n=3$ brains, 42 sections; Bcl11b: wt, $n=5$ brains, 63 sections; DSCAM ${ }^{\text {del17 }}$ mutant, $n=5$ brains, 63 sections; Tbr1: wt, $n=4$ brains, 49 (Figure legend continues.) 
DSCAM protein levels in wt, heterozygous, and mutant cortical tissue using Western blot analysis. DSCAM protein was reduced by $>50 \%$ in heterozygous littermates and virtually eliminated in mutant cortex (Fig. 1I). These data indicate that the DSCAM del17 mutation results in a loss of DSCAM in the forebrain, leading to gross alterations in brain size and shape, but no severe disorganization of major brain structures.

DSCAM is abundantly expressed in the cortex and localizes to dendrites and synaptic plasma membranes

To explore the localization of DSCAM within the developing cortex, we first characterized the spatial and temporal expression of DSCAM messenger RNA (mRNA) using in situ hybridization. Radioactive RNA sense and antisense probes against the cytoplasmic domain of DSCAM were hybridized to coronal sections of E16.5, E18.5, P3, and P10 cortex (Fig. 2A-D). In embryonic brains, DSCAM mRNA was ubiquitously expressed in neurons throughout the developing cortical plate and subplate. After birth, DSCAM mRNA remained abundant throughout the cortex until P14 (Fig. 2C,D and data not shown), and was upregulated in specific cortical layers. No signal was detected upon hybridization with sense control probes (data not shown).

To identify which cortical layers express DSCAM, we generated layer-specific probes (Fishell and Hanashima, 2008) against Tbr1 (layer VI and subplate), Fezf2 (layer V), Sox 5 (layers V-VI) and Satb2 (layers II-IV). While DSCAM expression overlapped with a number of these layer-specific markers throughout development (data not shown), the highest levels of DSCAM mRNA were localized to regions with high Fezf2 expression (Fig. 2E-H). The colocalization of DSCAM with Fezf2, a transcription factor required for the specification of corticospinal motor neurons in layer V (Molyneaux et al., 2005), suggested that DSCAM is also highly expressed in this population of cortical pyramidal neurons.

To confirm the presence of DSCAM in layer $\mathrm{V}$ pyramidal neurons, we used FACS (fluorescent activated cell sorting) to purify mature, layer $\mathrm{V}$ pyramidal neurons derived from Thy1$Y F P-H$ transgenic mice (Feng et al., 2000) and RT-PCR to verify the expression of DSCAM transcripts in YFP+ neurons (Fig. $2 I-K)$. In the cortex, Thy1-YFP-H mice specifically express YFP in a subset of layer $\mathrm{V}$ pyramidal neurons under control of the Thyl promoter (Fig. 2I) (Feng et al., 2000; Porrero et al., 2010). In preparation for FACS, cortical slices from adult transgenic mice were enzymatically dissociated, labeled with PI to mark dead neurons, and sorted to purify YFP+ and PI- neurons, typically yielding 500,000 YFP+ pyramidal neurons (Fig. $2 J$ ). As a control, YFP - and PI - control neurons were separately sorted. RNA was prepared from both groups of sorted neurons and RTPCR showed that YFP $+/$ PI - neurons express both DSCAM and $\mathrm{Bcl11b}$, a transcription factor specifically localized to corticospinal motor neurons in layer V (Fig. 2K) (Arlotta et al., 2005). Bcl11b expression was analyzed in place of Fezf2 expression due to a substantial downregulation of Fezf2 transcripts in adult pyramidal neurons. It should also be noted that YFP - neurons

\section{$\leftarrow$}

(Figure legend continued.) sections; DSCAM ${ }^{\text {del17 }}$ mutant, $n=3$ brains, 35 sections. $\mathbf{O}-\boldsymbol{R}$, Coronal sections of wt $(\mathbf{O}, \mathbf{Q})$ and $D S C A M^{\text {del }} 7$ mutant $(\boldsymbol{P}, \boldsymbol{R}) \mathrm{P} 1$ cortex immunostained for $B \mathrm{BCl1b}\left(\boldsymbol{O}^{\prime \prime}, \boldsymbol{P}^{\prime \prime}\right.$, $\left.\mathbf{Q}^{\prime \prime}, \boldsymbol{R}^{\prime \prime}\right), \operatorname{Tbr} 1\left(\boldsymbol{O}^{\prime}, \boldsymbol{P}^{\prime}\right)$, and (utl1 $\left(\boldsymbol{Q}^{\prime}, \boldsymbol{R}^{\prime}\right)$ and counterstained with DAPI $(\boldsymbol{O}-\boldsymbol{R})$. Cut|1 + layers II/III is reduced in thickness $\left(\mathbf{Q}^{\prime \prime \prime}, \boldsymbol{R}^{\prime \prime \prime}\right)$, whereas $\mathrm{Bc} 111 \mathrm{~b}+$ layer $\mathrm{V}$ and Tbr1 + layer VI are normal in DSCAM ${ }^{\text {del17 }}$ mutants compared with wt $\left(\boldsymbol{O}^{\prime \prime \prime}\right.$ and $\left.\boldsymbol{P}^{\prime \prime \prime}\right)$. Mean $\pm S \mathrm{SE}^{* *} p<0.01$, ${ }^{* * *} p<0.001$ compared with wt (Student's $t$ test). Scale bars: (in $\boldsymbol{B}, \mathbf{D}, \mathbf{L}, \mathbf{O}) \boldsymbol{A}, \boldsymbol{B}, \mathbf{C}-\boldsymbol{F}, \boldsymbol{K}, \mathbf{L}, \mathbf{O}-\mathbf{R}, 200 \mu \mathrm{m}$; (in $\boldsymbol{H}, \boldsymbol{M}) \boldsymbol{H}, \boldsymbol{I}, \boldsymbol{M}, 100 \mu \mathrm{m}$. Arrowheads in $\boldsymbol{K}-\boldsymbol{M}$ mark TUNEL + cells. express DSCAM, suggesting that DSCAM is not restricted to layer $\mathrm{V}$ pyramidal neurons. In addition, YFP - neurons also display expression of Bcl11b as only a subset of layer $\mathrm{V}$ pyramidal neurons is labeled with YFP in Thyl-YFP-H transgenic mice.

We next sought to determine a time course of DSCAM protein expression in the developing postnatal cortex. Using our DSCAM polyclonal antibody, we probed cortical lysates for DSCAM expression (Fig. 2L). DSCAM protein appeared to be dynamically regulated during cortical development with a peak in expression at P7-P10, a period characterized by robust pyramidal cell dendrite outgrowth and branching. After P10, DSCAM protein expression decreased with low abundance into adulthood.

To explore the possibility that DSCAM might contribute to pyramidal dendrite and spine morphogenesis, we investigated its protein localization at dendrites and synaptic contacts using a biochemical approach, subcellular fractionation. Fractionation of adult forebrains revealed that DSCAM is highly enriched in synaptic plasma membranes (SPM) along with the synaptic proteins PSD-95 and SynCAM (Fig. 2M). Absence of GDI immunoreactivity in SPM confirms that there is no cross contamination of the different subcellular brain fractions. While DSCAM protein can also be detected in other fractions, including crude homogenate $(\mathrm{CH})$, crude lysate $(\mathrm{S} 1)$, synaptosomal supernatant (S2), synaptosomes (P2'), and synaptosomal membranes (LP1), it was not expressed in lysis supernatant (LS1) and was almost undetectable in myelin (M) fractions (Fig. 2M).

The localization and expression of DSCAM protein in the cortex is consistent with a possible role for DSCAM in regulating cortical circuit formation, including dendrite arborization, spine formation, and synaptogenesis of layer $\mathrm{V}$ pyramidal neurons.

\section{Changes in cortical organization in DSCAM $M^{d e l 17}$ mutant brains}

Before analyzing DSCAM ${ }^{\text {del17 }}$ mutant pyramidal neurons for defects in dendrite and spine development, we first sought to examine the general organization of developing mutant cortices. Cortical thickness was significantly reduced at $\mathrm{P} 1$ in mutant compared with wt animals (Fig. $3 A, B, G ; 547.7 \pm 4.8$ and $601.9 \pm 11.3$ $\mu \mathrm{m}$, respectively; $p<0.0001$; Student's $t$ test). This reduction in cortical thickness persisted at P10 (Fig. 3 C,D, G; $948.5 \pm 17.2$ and $1013 \pm 12.3 \mu \mathrm{m}$, respectively; $p=0.0023$; Student's $t$ test); however, thickness of mutant cortex was similar to that of wt cortex at P17, P21, and P42 (Fig. 3 E-G; for P17: $1019 \pm 16.08$ and $1037 \pm 16.79 \mu \mathrm{m}$; for P21: $983.6 \pm 13.92$ and $1025 \pm 15.71 \mu \mathrm{m}$ and for P42: $1072 \pm 23.93$ and $1096 \pm 9.36 \mu \mathrm{m}$, respectively; $p>$ 0.05 ; Student's $t$ test).

Reductions in the cortical thickness of early postnatal mutants could be attributed to a decrease in neuron production or an increase in programmed cell death. We tested these possibilities by examining cell division and apoptosis in wt and mutant cortex. We first analyzed the number of S-phase cells capable of incorporating BrdU following a $30 \mathrm{~min}$ pulse in E16.5 wt (Fig. $3 \mathrm{H}$ ) and mutant (Fig. 3I) cortices. The average number of BrdU-positive cells per unit area in the ventricular zone was similar between wt and DSCAM ${ }^{\text {del17 }}$ mutants (Fig. 3J; three individual brains per genotype; wt: $161.8 \pm 3.62,175.6 \pm 1.14,161.3 \pm 7.40$ cells; mutant: $151.5 \pm 6.40,139.6 \pm 4.86,151.8 \pm 5.91$ cells). To examine the number of cells undergoing programmed cell death at P1, we used TUNEL staining to label cells at the end stage of apoptosis. There were very few TUNEL-positive cells in both wt (Fig. $3 K$ ) and mutant cortex (Fig. $3 L$ ). Indeed, there was no significant increase in cell death in DSCAM ${ }^{\text {del17 }}$ mutants (three individuals and 18 sections per genotype; wt: $0.50 \pm 0.14$; mutant: 
$0.83 \pm 0.31$ cells). We also saw no remarkable difference in the number of TUNEL-positive cells in wt or mutant cortex at E16.5 (data not shown). As a positive control, we observed TUNEL staining in $A C B D 3^{M y r}$ E12.5 cortex, a mouse model previously established as showing an increase in cortical cell death (Fig. 3M) (Zhou et al., 2007). These data suggest that decreases in neuron production and increases in cell death cannot significantly account for the reductions in cortical thickness in early postnatal mutants.

To determine whether changes in cortical lamination might account for cortical thinning in DSCAM ${ }^{\text {del17 }}$ mutant cortex, we immunostained wt and mutant $\mathrm{P} 1$ cortex with antibodies against the transcription factors Cutl1, Bcl-11b, and Tbr1, which are established markers for cortical layers II/III, V, and VI, respectively (Cubelos et al., 2010; Fishell and Hanashima, 2008; Arlotta et al., 2005). Bcl-11b and Tbr1-positive neurons occupied the same positions in both wt (Fig. 3O) and mutant cortices (Fig. 3P). Quantification of laminar thickness revealed that mutant cortex showed no significant difference in the thickness of Bcl11b+ (layer V) or Tbr1+ (layer VI) lamina compared with wt cortex (Fig. $3 N$; for Bcl11b: $118.9 \pm 1.5$ and $119.6 \pm 1.37 \mu \mathrm{m}$; for Tbr1: $205.5 \pm 4.33$ and $210.2 \pm 4.14 \mu \mathrm{m} ; p>0.05$; Student's $t$ test), demonstrating that DSCAM ${ }^{\text {del } 17}$ mutants have no significant defects in deep layer cortical lamination. Interestingly, the thickness of upper cortical layers II/III was significantly reduced in mutant cortices (Fig. 3R) compared with wt cortices (Fig. 3Q). Quantification showed that mutant mice have a $24 \%$ reduction in the thickness of Cutl1 + lamina (layers II/III) in the cortex compared with wt mice (Fig. $3 N$; $139.9 \pm 5.39$ and $183.2 \pm 5.12 \mu \mathrm{m}$, respectively; $p<0.0001$; Student's $t$ test).

These data suggest that DSCAM ${ }^{\text {del17 }}$ mutant mice show initial impairments in cortical thickness that may be explained by a thinning of cortical layers II/III. However, lamination in cortical layers $\mathrm{V}$ and VI remains intact.

\section{Alteration of dendrite arborization in pyramidal cells lacking DSCAM}

Having examined DSCAM ${ }^{\text {del17 }}$ mutant brains for changes in cortical organization, we next sought to investigate the role of DSCAM in pyramidal neuron morphogenesis. We focused our analysis on layer $\mathrm{V}$ pyramidal neurons given that DSCAM is upregulated in cortical layer $\mathrm{V}$, and thickness of this layer remains intact in DSCAM ${ }^{\text {del17 }}$ mutant brains. To determine whether DSCAM ${ }^{\text {del17 }}$ mutants had defects in cortical dendrite arborization, we used Golgi-Cox staining and camera lucida reconstruction to examine dendrite outgrowth and branching of layer $\mathrm{V}$ pyramidal neurons in motor and somatosensory cortex. Both Sholl and morphometric analyses revealed that layer V pyramidal neurons in P10 DSCAM ${ }^{\text {del17 }}$ mutant mice show changes in apical and basal dendrite arbors compared with wt littermates (Fig. $4 A, B, G-L)$. At P10, when DSCAM is at its peak expression, mutant pyramidal neurons showed a $25 \%$ increase in the number of apical branchpoints (Fig. 4A,B,G) compared with neurons derived from wild-type littermates. This increase in the number of apical dendrite branches was accompanied by a $15 \%$ decrease in mean apical dendrite branch length (Fig. 4I). The total length of basal dendrite arbors was also significantly reduced in P10 DSCAM ${ }^{\text {del17 }}$ mutant layer $\mathrm{V}$ pyramidal neurons (Fig. 4J). For apical and basal dendrite branching, Sholl analysis revealed a significant decrease in the number of intersections at $50 \mu \mathrm{m}$ for mutant neurons compared with wt neurons (Fig. $4 K-L$; for apical dendrites: $1.93 \pm 0.13$ and $2.4 \pm 0.22 \mu \mathrm{m} ; p=0.047$; for basal dendrites: $2.19 \pm 0.29$ and $3.42 \pm 0.41 \mu \mathrm{m} ; p=0.02$; Student's $t$ tests). Interestingly, the total length of apical dendrite branches was not significantly different between wt and mutant littermates (Fig. 4H). Total dendrite length and length of the primary apical dendrite was also similar for wt and mutant neurons (data not shown).

To explore whether these apical and basal dendrite branching defects were developmentally regulated, we examined pyramidal neuron dendrite structure at P17, one week after DSCAM reaches its peak expression. We found that mutant layer $\mathrm{V}$ pyramidal neurons still had a significant increase in the number of apical branchpoints at P17 (Fig. 4C,D, G). However, this increase in the number of apical branches was no longer accompanied by a significant decrease in mean apical dendrite branch length (Fig. 4I). Given that mutant pyramidal neurons now had additional apical branches of normal length, they displayed a significant increase in the total length of apical dendrite branching (Fig. $4 H$ ) and total dendrite length (data not shown) compared with wt neurons. Interestingly, basal dendrite arbors appeared to recover by P17, as there were no significant differences between wt and mutant neurons in the total length of basal dendrites (Fig. $4 \mathrm{~J}$ ).

To determine whether changes in apical dendrite branching persisted into adulthood in DSCAM ${ }^{\text {del17 }}$ mutants, we examined layer V pyramidal neuron morphology at P42, an age when dendrite arbors are mostly stable. We found that by P42, mutant pyramidal neurons were morphologically similar to wt neurons (Fig. $4 E, F$ ). Thus, at $\mathrm{P} 42$ there were no significant differences in the number of apical branchpoints (Fig. $4 G$ ), the mean length of apical branches (Fig. 4I), the total length of apical branches (Fig. $4 H$ ), and basal dendrites (Fig. $4 J$ ) or dendrite length (data not shown). Furthermore, Sholl analysis revealed no significant differences in apical or basal dendrite branching between wt and mutant mice (Fig. $4 K-L$ ). Together, these data demonstrate that dendrite arborization in DSCAM del17 mutants is initially impaired. However, both apical and basal dendrite arbors fully recover over time, such that DSCAM ${ }^{\text {del17 }}$ mutants display normal pyramidal neuron dendrite morphology by adulthood.

To determine whether reductions in the complexity of DSCAM ${ }^{\text {del17 }}$ mutant dendrite arbors occurred in a cell-autonomous fashion, wt and mutant neurons were dissociated from E16.5 cortex, transfected with GFP, cultured for $3 \mathrm{~d}$ in vitro, and analyzed for changes in the number and length of primary, secondary, and tertiary pyramidal neuron dendrite branches. DSCAM ${ }^{\text {del17 }}$ mutant cortical neurons (Fig. 5D-F) showed significant alterations in dendrite arborization compared with wt cortical neurons (Fig. 5A-C). In particular, mutant neurons displayed a significant decrease in the total length of secondary branches (Fig. 5G; $67.62 \pm 5.00$ and $94.47 \pm 7.54 \mu \mathrm{m}$, respectively; $p=$ 0.003 ; Student's $t$ test) accompanied by a significant decrease in the total number of secondary branches (Fig. $5 \mathrm{H} ; 4.24 \pm$ 0.26 and $5.37 \pm 0.29$ branches, respectively; $p=0.0045$; Student's $t$ test). These data confirm that DSCAM $M^{\text {dell7 }}$ mutant pyramidal neurons show impairments in dendrite arborization independent of global changes in cortical thickness or lamination.

\section{Increases in spine density on $D S C A M^{d e l 17}$ mutant apical dendrite branches}

Given the impairments in dendrite arborization in layer V pyramidal neurons in DSCAM ${ }^{\text {del17 }}$ mutant mice, we were interested to explore whether mutant apical dendrites exhibit any abnormalities is spine development. To visualize spines, we crossed DSCAM ${ }^{\text {del17 }}$ mice to Thy1-YFP-H mice to obtain wt and mutant DSCAM ${ }^{\text {del17 }}$-Thy1-YFP-H offspring. For the spine analyses, we 
A

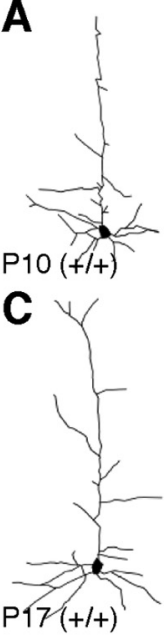

E
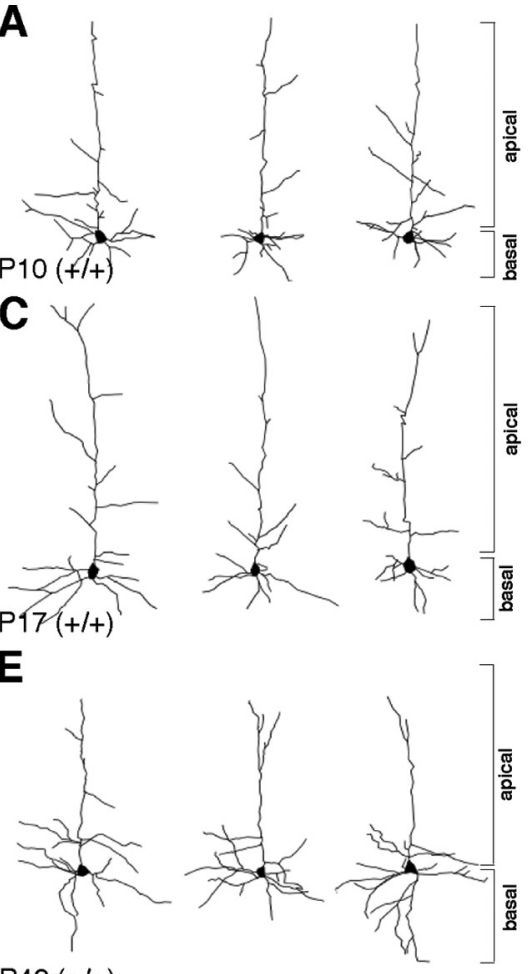

P42 (+/+)
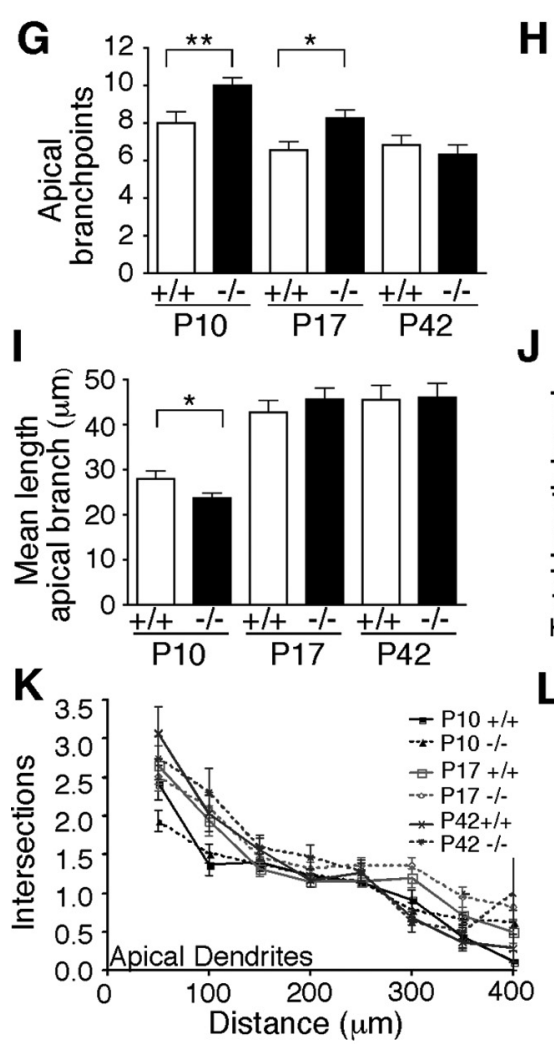

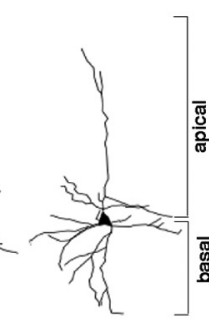

$P$

$\mathbf{F}$
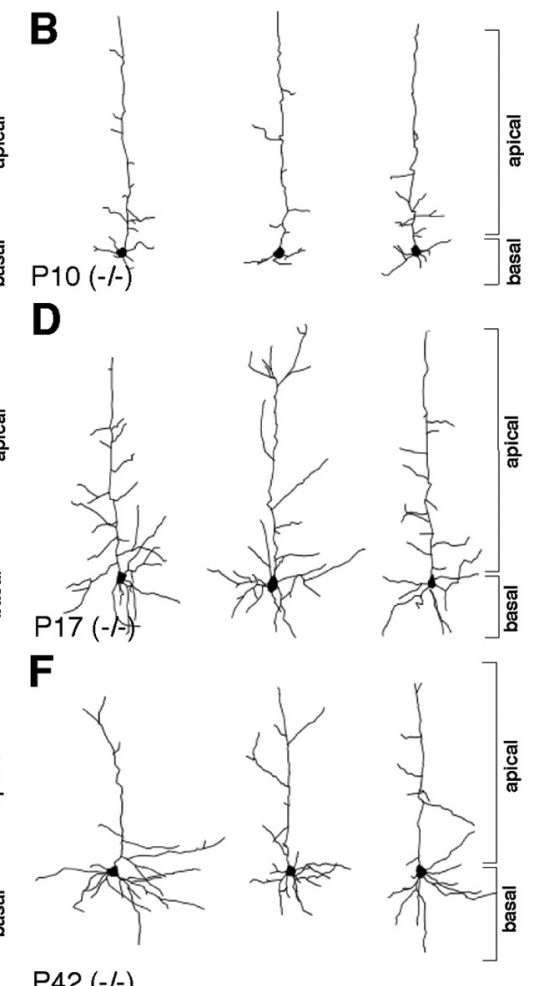

P42 (-1-)

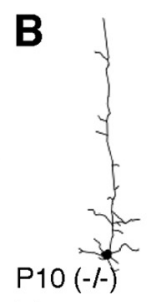

used fluorescence instead of Golgi-Cox staining because numerous studies have shown that Golgi staining misrepresents the true total number of spines on the dendritic shaft (Feldman and Peters, 1979; Shen et al., 2008). Additionally, use of a fluorescence transgene under control of the Thyl-promoter allowed us to examine spine number and morphology in a genetically defined population of layer $\mathrm{V}$ pyramidal neurons.

The earliest stage we could detect robust YFP expression in Thy1-YFP- $H+$ dendrites was at P15. Examination of spine density on P15 pyramidal neuron apical dendrite branches revealed that $D S C A M^{d e l 17}$ mutants show a $14 \%$ increase in spine density compared with wt littermates (Fig. $6 A, D ; 1.13 \pm$ 0.03 and $0.99 \pm 0.03$ spines per $\mu \mathrm{m}$, respectively; $p=0.0031$; Student's $t$ test). This increase in apical branch spine density was specific to P15 and was not observed at later developmental stages, including P21 (Fig. $6 B, D$ ) or $\mathrm{P} 42$ (Fig. $6 C, D$ ). While spine density was normal by adulthood in DSCAMdel17 mutants, many mutant apical branches exhibited subtle changes in spine distribution at P42. On mutant branches, spines could often be found clustered together, and they were less uniformly localized along the dendritic shaft compared with branches in wt genotype (Fig. 6C, arrows).

These data suggest that alterations in mutant pyramidal neuron apical dendrite arborization are accompanied by increases in apical branch spine density in early development. As development progresses, spine density recovers to normal, but there may be lasting changes in spine distribution and morphology that impact pyramidal neuron function and wiring.

\section{Aberrant morphology of dendritic spines in $D S C A M^{\text {dell7 }}$ mutants}

Regulation of spine morphology is closely associated with synaptogenesis and the establishment of functional connectivity between neuronal networks. Given that $D{ }^{2} C A M^{\text {dell7 }}$ mutants showed early abnormalities in spine density, we investigated whether these differences in spine number

\section{$\leftarrow$}

measures dendrite complexity: concentric threedimensional shells of increasing radius are centered on the cell body of the neuron; the number of intersections of the dendrite arbor with a given shell is plotted versus the radius of the shell. Each point represents mean \pm SE.P10:wt, $n=$ 4 mice, 35 neurons; DSCAM del 17 mutant, $n=5$ mice, 62 neurons; P17: wt, $n=5$ mice, 32 neurons; DSCAM del17, $n=5$ mice, 46 neurons; P42: wt, $n=3$ mice, 30 neurons; DSCAM del17,$n=4$ mice, 32 neurons. Mean $\pm S E,{ }^{*} p<0.05$; ${ }^{* *} p<0.01$ compared with wt (Student's t test).
Figure 4. Alterations of dendrite arbor development in DSCAM del17 mutants. $A-F$, Camera lucida drawings of representative wt $(\boldsymbol{A}, \boldsymbol{C}, \boldsymbol{E})$ and $D S C A M^{\text {del17 }}$ mutant $(\boldsymbol{B}, \boldsymbol{D}, \boldsymbol{F})$ layer V pyramidal neurons from P10 $(\boldsymbol{A}, \boldsymbol{B}), \mathrm{P} 17(\boldsymbol{C}, \boldsymbol{D})$, and P42 $(\boldsymbol{E}, \boldsymbol{F})$ mice. $\mathbf{G}-\boldsymbol{I}$, Mean branch point number $(\boldsymbol{G})$, total length $(\boldsymbol{H})$, and individual branch length $(\boldsymbol{I})$ of apical dendritic arbors from wt and DSCAM del7 mutant layer V pyramidal neurons at $\mathrm{P} 10, \mathrm{P} 17$, and $\mathrm{P} 42$. There is a significant increase in apical branch point number in DSCAM del17 mutants at P10 and P17. DSCAM ${ }^{\text {del17 }}$ mutants show a significant decrease in mean length of individual apical branches and total length of basal dendrite arbors at P10. The total length of apical branches is significantly increased in P17 DSCAM del17 mutants compared with wt. $J$, Mean total length of basal dendrite arbors from wt and DSCAM ${ }^{\text {del17 }}$ mutant layer V pyramidal neurons at $P 10$ $\mathrm{P} 17$, and $\mathrm{P} 42$. Basal dendrite arbors are significantly reduced in DSCAM del17 mutants at $\mathrm{P} 10$, but are normal at $\mathrm{P} 17$ and $\mathrm{P} 42 . \mathbf{K}-\mathbf{L}$ Sholl analysis of apical $(\boldsymbol{K})$ and basal $(\boldsymbol{L})$ dendrites from wt and DSCAM ${ }^{\text {del17 }}$ mutant layer V pyramidal neurons. Sholl analysis 

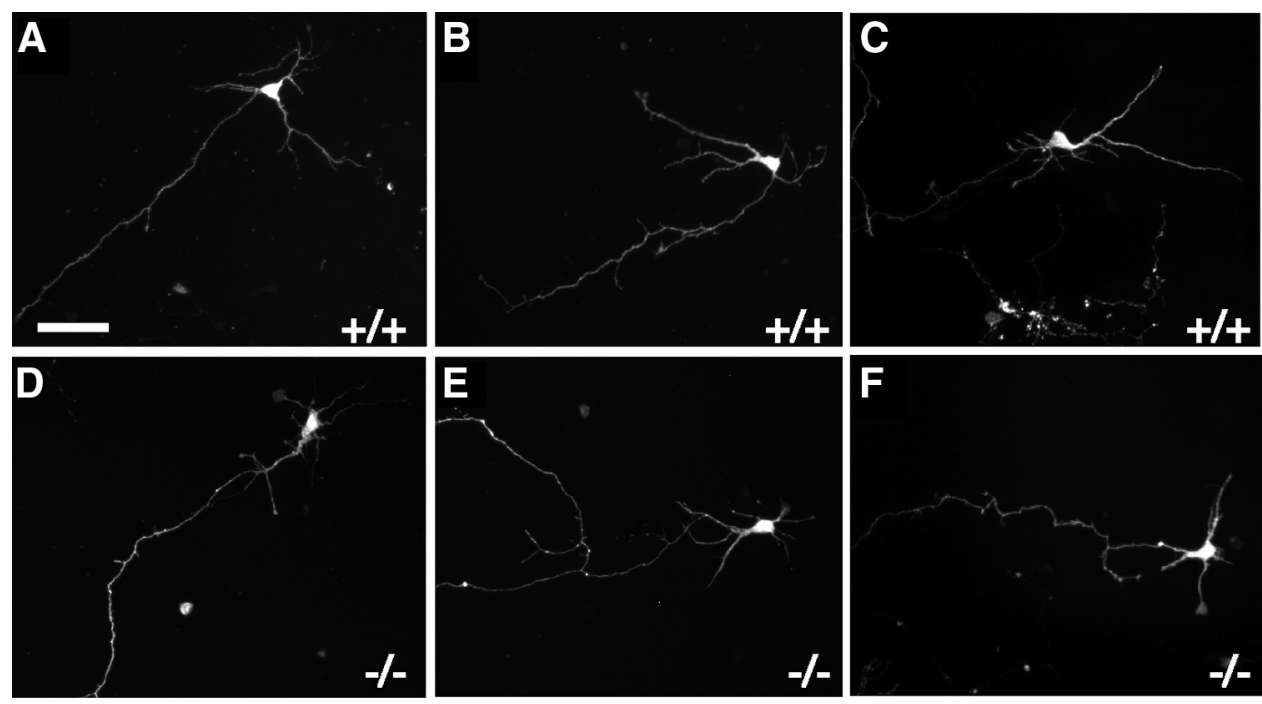

G

H
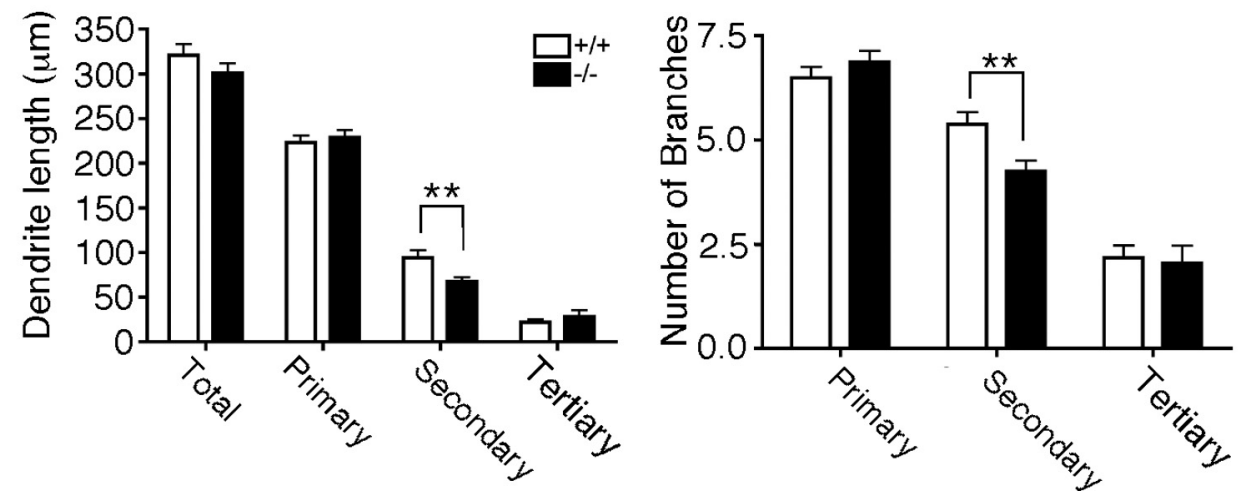

Figure 5. Reduction of dendrite complexity in DSCAM del17 mutant neurons is cell autonomous. $A-F$, Fluorescent micrographs of representative GFP-expressing wt $(\boldsymbol{A}-\boldsymbol{C})$ and $D S C A M^{\text {del } 17}$ mutant $(\boldsymbol{D}-\boldsymbol{F})$ cortical neurons isolated from E16.5 cortex and cultured for $3 \mathrm{~d}$ in vitro. G-H, Morphometric analysis of dendrite length and branching in wt and mutant GFP-expressing cultured cortical neurons. Total primary, secondary, and tertiary dendrite length $(\boldsymbol{G})$ and number of dendrite branches $(\boldsymbol{H})$ for wt and DSCAM ${ }^{\text {del } 17}$ mutant cortical neurons. DSCAM ${ }^{\text {dell7 }}$ mutant neurons show significant decreases in the total length and number of secondary dendrite branches compared with wt neurons. Analysis was performed on two different litters: wt, $n=4$ brains, 88 neurons; DSCAM ${ }^{\text {del } 17}$ mutant, $n=5$ brains, 96 neurons. Mean $\pm S E_{,}^{* *} p<0.01$ compared with wt (Student's $t$ test). Scale bar: (in $\left.A\right) A-F, 50 \mu \mathrm{m}$.

correlated with changes in spine morphology. To characterize the structure of developing dendritic spines, we measured both the height and the width of spine heads of DSCAM dell7 - Thy1-YFP-H apical dendrite branches at P15, P21, and P42. For both measurements, spines were classified by size and binned to generate frequency diagrams representing the percentage of differently sized spine populations along a segment (Belichenko et al., 2009).

Analysis of spine morphology on P15 apical branches showed that $D S C A M^{\text {del17 }}$ mutant branches had a marked increase in the percentage of shorter spines $(0.5-1 \mu \mathrm{m})$ and a $23 \%$ decrease in the percentage of longer spines (1.5-2 $\mu \mathrm{m})$ compared with wt branches (Fig. $7 A, B$; for bin 1.5-2 $\mu \mathrm{m}$ : $9.812 \pm 0.6584$ and $12.79 \pm 0.8424 \%$, respectively; $p=0.0062$; Student's $t$ test). In mutant brains (Fig. 7A, bottom, $B, C$ ), a reduction in spine height was accompanied by a reduction in spine head size as indicated by a $16 \%$ increase in the density of spines heads $<0.3 \mu \mathrm{m}$ in width compared with wt (Fig. 7 A, $C ; 39.02 \pm 1.66$ and $33.63 \pm 1.46 \%$, respectively; $p=0.017$; Student's $t$ test). Thus, frequency diagrams at P15 suggested an increase in the percentage of short, small spines and a decrease in the percentage of large spines on mutant apical branches.

By P21, aberrant spine morphologies were less obvious and there were no significant differences in the percentage of shorter or longer spines, and no significant differences in the percentage of bigger or smaller spine heads (Fig. $7 D-F$ ). However, there was still a trend for an increase in the percentage of spines between 0.5 and $1 \mu \mathrm{m}$ in height (Fig. 7E) as observed at P15. The lack of significant differences in spine populations at P21 may be reflective of a dynamic period of transient growth and pruning as observed for dendrite arborization at P17 (Fig. 5C,D,I).

Interestingly, by adulthood, $D S C A M^{\text {dell7 }}$ mutants again display significant alterations in spine structure indicative of an increase in the percentage of small, immature spines and a decrease in the percentage of large, stable spines. At P42, mutant apical branches showed a $16 \%$ increase in the density of spines $<0.5 \mu \mathrm{m}$ in height compared over wt (Fig. $7 G, H ; 17.06 \pm 0.89$ and $14.67 \pm 0.70 \% ; p=$ 0.0372 ; Student's $t$ test) and a strong trend for an increase in spine density between 0.5 and $1 \mu \mathrm{m}$ in height compared with wt. There were also strong trends for decreases in the percentage of longer spines in all larger bins. Similarly, mutant branches showed an increase in the percentage of spine heads between 0.2 and $0.4 \mu \mathrm{m}$ compared with wt (Fig. 7G,I; $46.63 \pm 1.38$ and $41.78 \pm 1.18 \%$; $p=$ 0.01 ; Student's $t$ test), and a significant decrease in the density of spine heads between 0.4 and $0.6 \mu \mathrm{m}$ in width compared with wt (Fig. $7 G, I ; 29.89 \pm 1.46$ and $34.13 \pm 1.09 \% ; p=0.022$; Student's $t$ test). These results are consistent with observations at P15. 


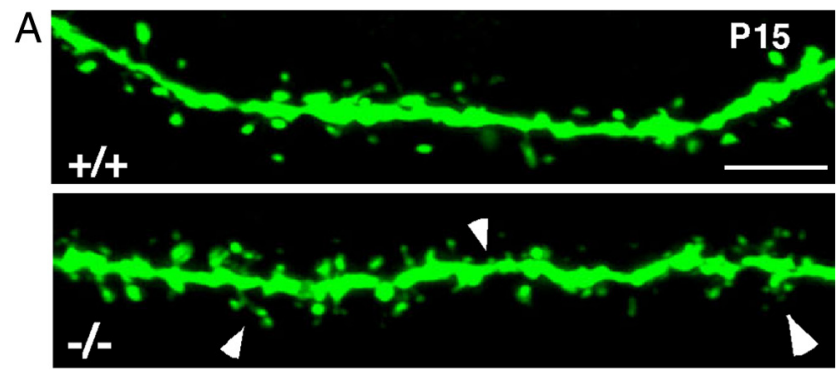

B
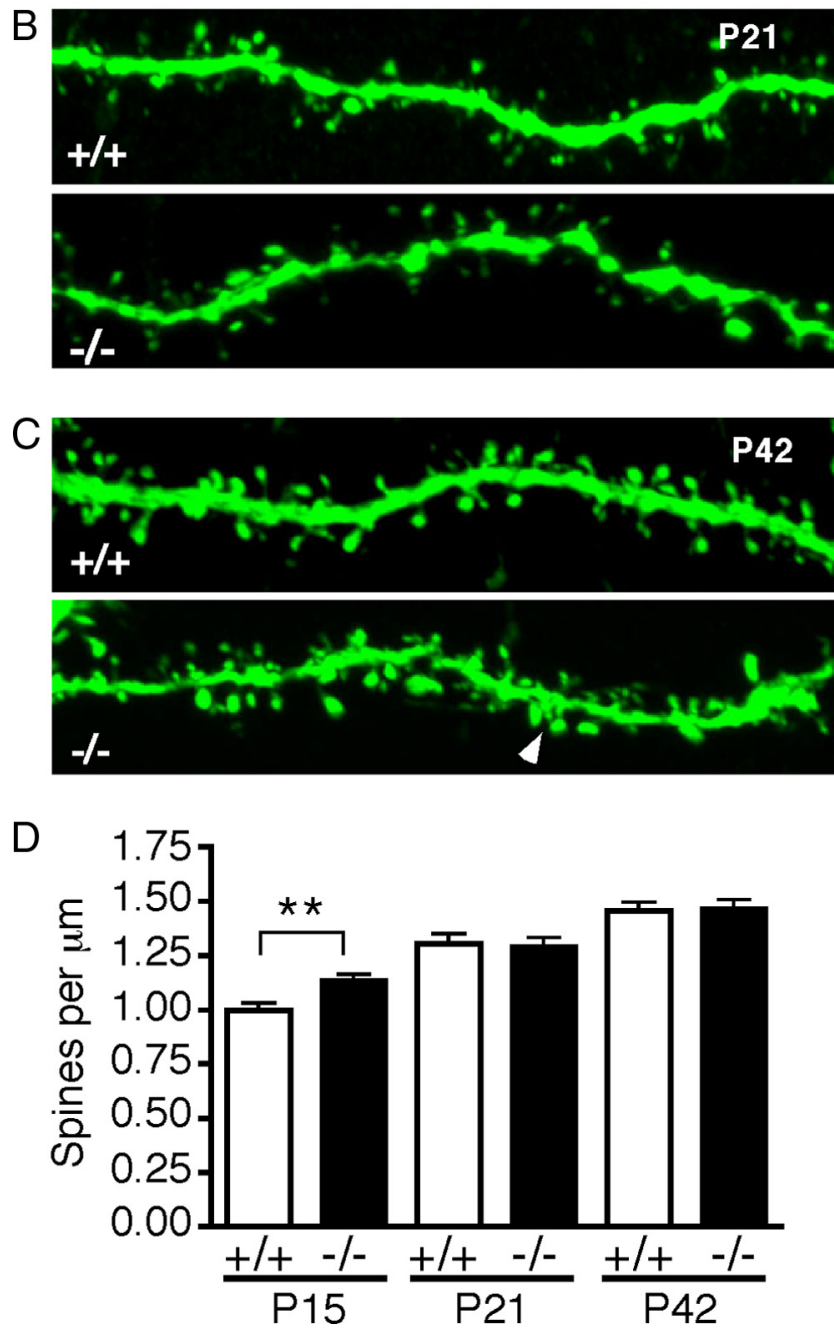

Figure 6. Early postnatal DSCAM del17-Thy1-YFP-H mutants have a transient increase in apical branch spine density. $\boldsymbol{A}-\boldsymbol{C}$, Confocal Z-projections of representative DSCAM ${ }^{\text {del17 }}$ wt (top panels) and mutant (bottom panels) apical branches on YFP-labeled layer V pyramidal neurons at P15 (A), P21 (B), and P42 (C).D, Quantification of spine density (spines per micrometer) on wt and DSCAM del17 mutant apical branches at P15, P21, and P42. Apical branch spine density is increased in DSCAM del17 mutants at P15, but recovers to normal by P21. Spine density remains stable into adulthood, but mutant branches often show abnormally distributed and clustered spines at P42 (indicated by arrows in bottom panel of C.P15, P21, and P42, $n=3$ mice and 60 neurons per genotype per time point). For each neuron, spine density is the average of two apical branches. Arrowheads indicate spine increases $(\boldsymbol{A})$ and spine clustering (C). Mean $\pm \mathrm{SE}$, ${ }^{* *} p<0.01$ compared with wt (Student's $t$ test). Scale bar: (in $\left.A\right) A-C, 5 \mu \mathrm{m}$.

Overall, examination of temporal changes in spine morphology in DSCAM ${ }^{\text {dell }}$ mice had significant changes in the size of dendritic spines at mutant apical branches. In early development and adulthood, mutants displayed a significant increase in the percentage of short, small spines and a significant decrease in the percentage of long, large spines. These alterations in spine development accompany changes in dendrite arborization and likely result in abnormalities in pyramidal neuron synaptogenesis and wiring.

\section{Discussion}

Our results indicate that DSCAM is dynamically expressed during cortical development and plays an important role in pyramidal neuron dendrite arborization and spine morphogenesis. DSCAM ${ }^{\text {del17 }}$ mutant mice show early impairments in layer V pyramidal neuron dendrite branching and aberrancies in apical dendrite spine density and morphology. Defects in dendrite and spine structure have been associated with abnormalities in cortical wiring in a number of cognitive disorders, including DS (Benavides-Piccione et al., 2004), thus our results implicate DSCAM as an important contributor to pyramidal neuron morphogenesis and circuit formation during cortical development.

\section{Gross morphological differences in $D S C A M^{\text {del17 }}$ mutants}

$D_{S C A}{ }^{\text {del17 }}$ mutant mice showed a dramatic reduction in body size accompanied by significant increases in brain weight, resulting in an elevated brain to body weight ratio at both P10 and P42 (Fig. $1 \mathrm{~J}$ ). Furthermore, mutants showed abnormalities in brain shape that were apparent during early development and persisted into adulthood. Interestingly, a small number of DSCAM del17 mutant exhibited minor hydrocephalus that resulted in enlargement of the lateral ventricles (data not shown). Xu et al. (2011) recently reported that $D S C A M^{\text {dell7 }}$ mutant mice have severe hydrocephalus, cortical thinning, and a decrease in motor function. However, in our breeding colony, which had a mixed DBA2/129 background, the presence of hydrocephalus was rare, and any mutant with a severe ventricular enlargement or collapsed brain was excluded from the analysis. Despite the observation that nonhydrocephalus DSCAM ${ }^{\text {del17 }}$ mutants still exhibited differences in overall brain size and shape, Nissl staining and volumetric analysis showed that regions of the cortex and other subcortical structures remained intact and normally organized. While there were significant reductions in the volume of the hippocampus and posterior regions of the cortex, the volume of the anterior cortical regions and the thalamus were not significantly altered. As DSCAM ${ }^{\text {del17 }}$ mutants exhibit only a $70 \%$ reduction in DSCAM mRNA by Northern blotting (Fuerst et al., 2008), we wanted to determine whether this mRNA reduction resulted in a decrease in DSCAM protein in the mutant cortex. Indeed, we did not detect any DSCAM protein in cortical lysates derived from mutant brains using our polyclonal antibody that targets the last 100 aa of DSCAM (Fig. 1I).

\section{Expression of DSCAM in the cortex is}

developmentally regulated

While DSCAM mRNA had been previously localized to the developing cortex at early embryonic and adult stages (Barlow et al., 2002), the present study is the first to carefully examine the spatiotemporal expression of DSCAM mRNA in the cortex during early postnatal development. Our results show that DSCAM mRNA is robustly expressed throughout the nascent cortical plate, and is particularly upregulated in corticospinal motor neurons occupying layer V. Temporal analysis of DSCAM protein expression revealed that DSCAM is dynamically expressed during development and peaks $\sim 7-10 \mathrm{~d}$ after birth. This developmental time point marks a period of robust dendrite outgrowth, spine formation, and synaptogenesis in layer V pyramidal neurons (Romand et al., 2011). Investigation of DSCAM localization in the cortex by subcellular fractionation demonstrated that DSCAM is present at synaptic 
A

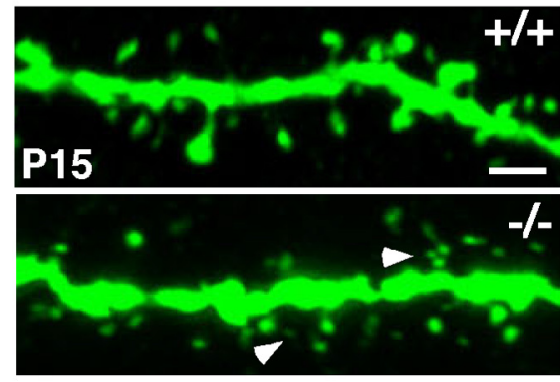

D
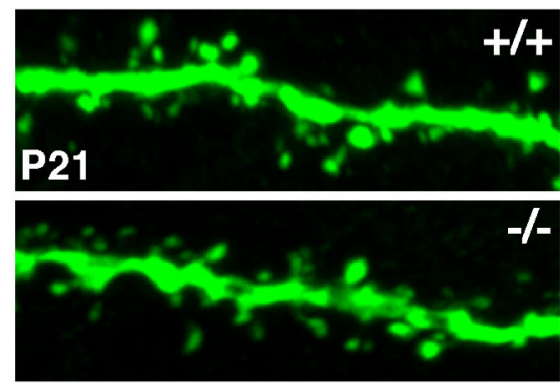

G
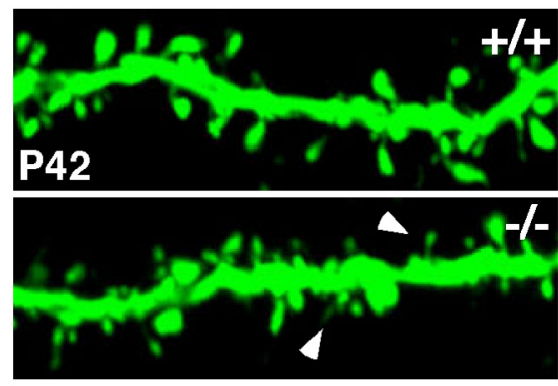

B

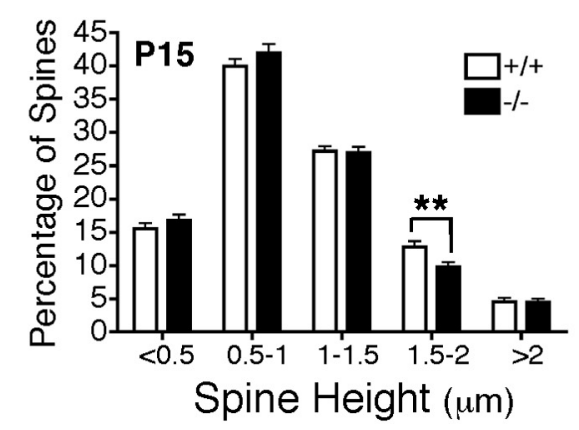

E

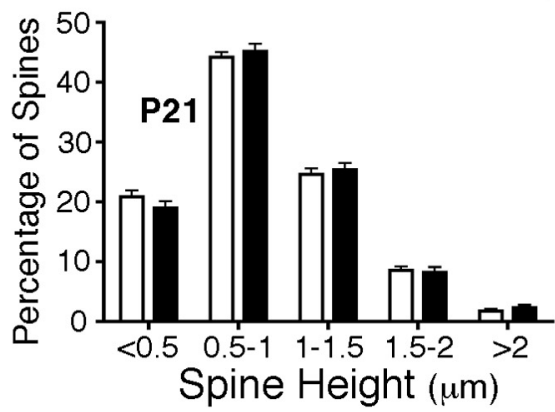

$\mathrm{H}$

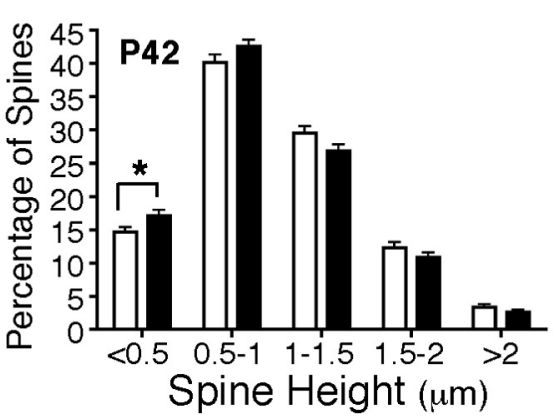

I
C

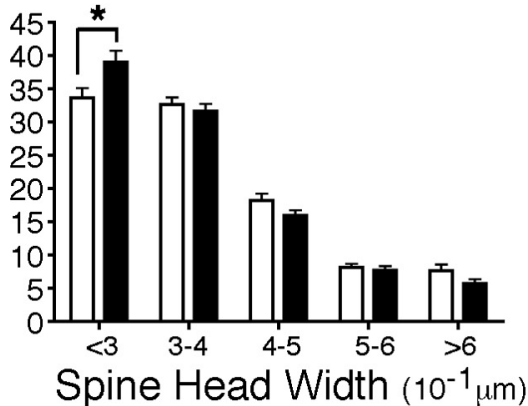

F

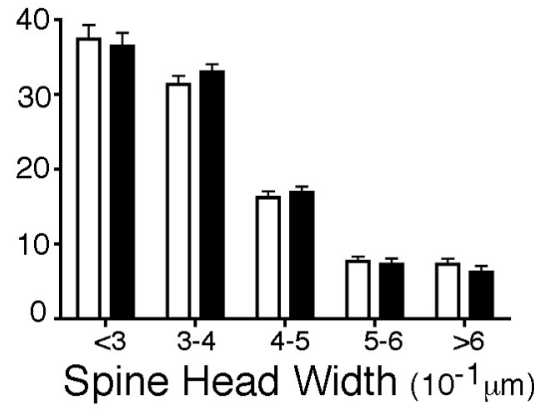

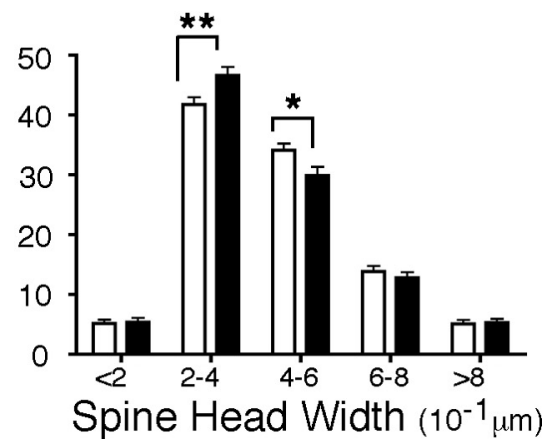

Figure 7. DSCAM dell7 mice display transient changes in the morphology of dendritic spines. $A, D, G$, High-magnification confocal Z-projections of representative DSCAM dell7 ${ }^{\text {wt }}$ (top panels) and mutant (bottom panels) apical branches on YFP-labeled layer V pyramidal neurons at P15 (A), P21 (D), and P42 (G). B, E, H, Frequency diagrams of spine height size at P15 (B), P21 (E), and P42 (H). During postnatal development, DSCAM del17 mutants show a significant decrease in the percentage of long spines, and a significant increase in proportion of short spines. Frequency diagrams of spine head width at P15 (C), P21 $(F)$, and P42 (D). For DSCAM del17 mutants, developmental changes in spine height are accompanied by significant increases in the percentage of small spine heads and significant decreases in the percentage of large spine heads. P15, $n=3$ mice, 46 neurons, 60 branches per genotype; $P 21, n=3$ mice, 48 neurons, 60 branches per genotype; $P 42, n=3$ mice, 46 neurons, 60 branches per genotype. Arrowheads in $A$ and $\mathbf{G}$ indicate small, short spines. Mean $\pm S E,{ }^{*} p<0.05,{ }^{* *} p<0.01$ compared with wt littermates (Student's t test). Scale bar: (in A) A, D, G, $2 \mu \mathrm{m}$.

plasma membranes in neurons, indicating an enrichment of DSCAM on dendrites and dendritic spines. Together, our data uniquely suggest that DSCAM is temporally and spatially positioned to contribute to pyramidal neuron dendrite development.

Early reductions in cortical thickness exhibit developmental recovery in DSCAM ${ }^{\text {del17 }}$ mutant mice

Given the gross morphological changes in brain size and shape in $D S C A M^{\text {dell7 }}$ mutants, it was necessary to examine the general structure and organization of the cortex. Mutants had significantly thinner cortices early in postnatal development, but normal cortical thickness by late postnatal development and into adulthood. We ruled out the possibility that $D S C A M^{d e l 17}$ mutant cortices showed an alteration in thickness due to a decrease in neuron production at E16.5 or an increase in programmed cell death at $\mathrm{P} 1$. Analysis of the lamination in mutant cortices showed that thinning of upper cortical layers II/III accounts for initial impairments in cortical thickness (Fig. 3N). It is possible that temporary reductions in neuropil may also contribute to transient decreases in cortical thickness. This hypothesis is highly consistent with our results, which show that apical and basal dendrite arbors of pyramidal neurons are initially impaired, but recover to normal by adulthood.

\section{Defects in pyramidal neuron dendrite arborization in} DSCAM ${ }^{\text {del17 }}$ mutants

A few guidance molecule systems have been previously implicated in cortical pyramidal neuron dendrite growth and arborization. Semaphorin 3a (Sema3a) has been shown to orient pyramidal neuron apical dendrites and regulate the length and branching of pyramidal apical and basal dendrite arbors (Polleux et al., 2000, Fenstermaker et al., 2004). Additionally, Slit/Robo signaling has been implicated in dendrite remodeling by mediating an increase in cortical dendrite length and branching (Whitford et al., 2002). Our results suggest that DSCAM can now be 
added to this list of guidance molecules that contribute to pyramidal neuron dendrite development in the cortex.

$D S C A M^{\text {dell7 }}$ mutant pyramidal neurons show significant alterations in apical and basal dendrite arborization in early postnatal development. At $10 \mathrm{~d}$ after birth, mutant pyramidal neurons display apical arbors possessing an increase in branch number accompanied by a decrease in branch length. Mutant basal dendrite arbors are also significantly reduced at this age. Over time, these defects in dendrite arborization recover such that mutants display normal apical and basal dendrite arbors by adulthood. One possible explanation for this developmental recovery of dendrite arborization is the upregulation of molecules that may be functionally redundant for DSCAM, including other Ig-receptors, or the DSCAM paralog DSCAML1 (DSCAM like-1). We have in situ hybridization and protein expression data showing that DSCAML1 is highly expressed in the developing cortex in a spatiotemporal pattern similar to that of DSCAM (data not shown). Furthermore, DSCAML1 has also been implicated in dendrite and synapse development in the vertebrate retina (Yamagata and Sanes, 2008; Fuerst et al., 2009) and may play a similar role in the cortex. Given that we observed significant increases in apical dendrite branch number in $D S C A M^{\text {dell }}$ mutant neurons at two developmental stages, one hypothesis is that DSCAM functions to limit branch initiation on the primary apical dendrite. This interpretation would be consistent with work in Drosophila showing that DSCAM controls branching and bifurcation of axons in the mushroom body (Wang et al., 2002) and also propose a novel role for DSCAM in pyramidal neuron dendrite development. Whereas Sema3a and Slit/Robo have been shown to promote dendrite outgrowth and branching (Polleux et al., 2000; Fenstermaker et al., 2004; Whitford et al., 2002), our results suggest that DSCAM may have a different function to limit the formation of ectopic apical branches. It is likely that DSCAM works in collaboration with other guidance molecules to orchestrate pyramidal dendrite arborization. Future studies aim to investigate the mechanism by which DSCAM influences pyramidal dendrite arborization, and whether DSCAM works in conjunction with Semaphorins and Slits to regulate pyramidal dendrite morphology.

\section{Defects in spine density and morphogenesis on mutant apical branches}

While DSCAM has been previously implicated in synaptogenesis and synaptic plasticity in a number of neuronal circuits (Yamagata and Sanes, 2008; Li et al., 2009; Alves-Sampaio et al., 2010; Millard et al., 2010; Zhu et al., 2011), this is the first study implicating DSCAM in dendritic spine development. DSCAM ${ }^{\text {dell7 }}$ mutants exhibit transient increases in apical branch spine density that are correlated with lasting alterations in spine morphology, most notably increases in the density of small, stubby spines, and decreases in the density of large, mushroom-shaped spines. A large body of work has demonstrated that alterations in spine number and structure are associated with changes in synaptic strength, neuronal activity, and experience (for review, see Lippman and Dunaevsky, 2005). Decreases in the density of large, stable spines in DSCAM del17 mutants likely lead to impairments in synaptic development and plasticity.

Interestingly, few guidance molecules have been shown to govern spine formation on developing dendrites. Elimination of Semaphorin $3 \mathrm{~F}$ in the developing cortex results in increased spine densities and aberrant spine morphology in cortical pyramidal neurons (Tran et al., 2009). Additionally, mice lacking EphB1, EphB2, and EphB3 receptor tyrosine kinases fail to form mature spines on developing hippocampal dendrites (Henkemeyer et al., 2003). It is possible that DSCAM functions similar as the ephrin receptors and collaborates with NMDA receptors to contribute to spine and synapse formation, as suggested by the studies by Alves-Sampaio (2010).

\section{DSCAM and Down syndrome}

DSCAM is one of the over 350 genes localized on human chromosome 21 and one of the 33 genes located in the Down syndrome critical region on chromosome 21, a region of chromosome 21 that previously has been suggested to contain the genes that contribute to the pathogenesis of Down syndrome, including the mental retardation phenotype (Rahmani et al., 1990; Yamakawa et al., 1998). Postmortem studies of human DS brains have revealed that cortical pyramidal neurons display significant defects in dendrite arborization and spine formation during development, but the contribution of DSCAM to this syndrome has not been established (Marin-Padilla, 1976). Furthermore, many mouse models of DS display abnormalities in pyramidal neuron dendrite branching and spine morphogenesis (Benavides-Piccione et al., 2004; Belichenko et al., 2009). However, the specific contribution of DSCAM to these dendrite and spine defects remains unclear. Future studies aim to directly explore whether elevated levels of DSCAM lead to alterations in cortical wiring in mouse models of DS. Given the developmental regulation of DSCAM and its implication in pyramidal neuron dendrite arborization and spine formation, overexpression of DSCAM may significantly contribute to the DS phenotype.

\section{References}

Agarwala KL, Nakamura S, Tsutsumi Y, Yamakawa K (2000) Down syndrome cell adhesion molecule DSCAM mediates homophilic intercellular adhesion. Brain Res Mol Brain 79:118-126. CrossRef Medline

Alves-Sampaio A, Troca-Marín JA, Montesinos ML (2010) NMDAmediated regulation of DSCAM dendritic local translation is lost in a mouse model of Down's syndrome. J Neurosci 30:13537-13548. CrossRef Medline

Andrews GL, Tanglao S, Farmer WT, Morin S, Brotman S, Berberoglu MA, Price H, Fernandez GC, Mastik GS, Charron F, Kidd T (2008) DSCAM guides embryonic axons by netrin-dependent and -independent functions. Development 135:3839-3848. CrossRef Medline

Arlotta P, Molyneaux BJ, Chen J, Inoue J, Kominami R, Macklis JD (2005) Neuronal subtype-specific genes that control corticospinal motor neuron development in vivo. Neuron 45:207-221. CrossRef Medline

Belichenko NP, Belichenko PV, Kleschevnikov AM, Salehi A, Reeves RH, Mobley WC (2009) The "Down syndrome critical region" is sufficient in the mouse model to confer behavioral, neurophysiological, and synaptic phenotypes characteristic of Down syndrome. J Neurosci 29:5938-5948. CrossRef Medline

Benavides-Piccione R, Ballesteros-Yáñez I, Martinez de Lagrán M, Elston G, Estivill X, Fillat C, Defelipe J, Dierssen M (2004) On dendrites in Down syndrome and DS murine models: a spiny way to learn. Prog Neurobiol 74:111-126. CrossRef Medline

Biederer T, Sara Y, Mozhayeva M, Atasoy D, Liu X, Kavalali ET, Südhof TC (2002) SynCAM, a synaptic adhesion molecule that drives synapse assembly. Science 297:1525-1531. CrossRef Medline

Blank M, Fuerst PG, Stevens B, Nouri N, Kirkby L, Warrier D, Barres BA, Feller MB, Huberman AD, Burgess RW, Garner CC (2011) The Down syndrome critical region regulates retinogeniculate refinement. J Neurosci 31:5764-5776. CrossRef Medline

Broadbelt K, Byne W, Jones LB (2002) Evidence for a decrease in basilar dendrites of pyramidal cells in schizophrenic medial prefrontal cortex. Schizophr Res 58:75-81. CrossRef Medline

Cubelos B, Sebastián-Serrano A, Beccari L, Calcagnotto ME, Cisneros E, Kim S, Dopazo A, Alvarez-Dolado M, Redondo JM, Bovolenta P, Walsh CA, Nieto M (2010) Cux1 and Cux2 regulate dendritic branching, spine morphology, and synapses of the upper layer neurons of the cortex. Neuron 66:523-535. CrossRef Medline 
Feldman ML, Peters A (1979) A technique for estimating total spine numbers on Golgi-impregnated dendrites. J Comp Neurol 188:527-542. CrossRef Medline

Feng G, Mellor RH, Bernstein M, Keller-Peck C, Nguyen QT, Wallace M, Nerbonne JM, Lichtman JW, Sanes JR (2000) Imaging neuronal subsets in transgenic mice expressing multiple spectral variants of GFP. Neuron 28:41-51. CrossRef Medline

Fenstermaker V, Chen Y, Ghosh A, Yuste R (2004) Regulation of dendritic length and branching by semaphorin 3A. J Neurobiol 58:403-412. CrossRef Medline

Fishell G, Hanashima C (2008) Pyramidal neurons grow up and change their mind. Neuron 57:333-338. CrossRef Medline

Fuerst PG, Koizumi A, Masland RH, Burgess RW (2008) Neurite arborization and mosaic spacing in the mouse retina require DSCAM. Nature 451:470-474. CrossRef Medline

Fuerst PG, Bruce F, Tian M, Wei W, Elstrott J, Feller MB, Erskine L, Singer JH, Burgess RW (2009) DSCAM and DSCAML1 function in self-avoidance in multiple cell types in the developing mouse retina. Neuron 64:484497. CrossRef Medline

Glantz LA, Lewis DA (2000) Decreased dendritic spine density on prefrontal cortical pyramidal neurons in schizophrenia. Arch Gen Psychiatry 57:65-73. CrossRef Medline

Henkemeyer M, Itkis OS, Ngo M, Hickmott PW, Ethell IM (2003) Multiple EphB receptor tyrosine kinases shape dendritic spines in the hippocampus. J Cell Biol 163:1313-1326. CrossRef Medline

Horch HW, Krüttgen A, Portbury SD, Katz LC (1999) Destabilization of cortical dendrites and spines by BDNF. Neuron 23:353-364. CrossRef Medline

Hutsler JJ, Zhang H (2010) Increased dendritic spine densities on cortical projection neurons in autism spectrum disorders. Brain Res 1309:83-94. CrossRef Medline

Huttenlocher PR (1974) Dendritic development in neocortex of children with mental defect and infantile spasms. Neurology 24:203-210. CrossRef Medline

Jan YN, Jan LY (2003) The control of dendrite development. Neuron 40: 229-242. CrossRef Medline

Jones DH, Matus AI (1974) Isolation of synaptic plasma membrane from brain by combined flotation-sedimentation density gradient centrifugation. Biochim Biophys Acta 356:276-287. CrossRef Medline

Kaufmann WE, Moser HW (2000) Dendritic anomalies in disorders associated with mental retardation. Cereb Cortex 10:981-991. CrossRef Medline

Kim S, Chiba A (2004) Dendritic guidance. Trends Neurosci 27:194-202. CrossRef Medline

Li HL, Huang BS, Vishwasrao H, Sutedja N, Chen W, Jin I, Hawkins RD, Bailey CH, Kandel ER (2009) DSCAM mediates remodeling of glutamate receptors in Aplysia during de novo and learning-related synapse formation. Neuron 61:527-540. CrossRef Medline

Lippman J, Dunaevsky A (2005) Dendritic spine morphogenesis and plasticity. J Neurobiol 64:47-57. CrossRef Medline

Ly A, Nikolaev A, Suresh G, Zheng Y, Tessier-Lavigne M, Stein E (2008) DSCAM is a netrin receptor that collaborates with DCC in mediating the turning responses to netrin-1. Cell 133:1241-1254. CrossRef Medline

Marin-Padilla M (1976) Pyramidal cell abnormalities in the motor cortex of a child with Down's syndrome: A Golgi Study. J Comp Neurol 167:63-81. CrossRef Medline

Matthews BJ, Kim ME, Flanagan JJ, Hattori D, Clemens JC, Zipursky SL, Grueber WB (2007) Dendrite self-avoidance is controlled by DSCAM. Cell 129:593-604. CrossRef Medline

Millard SS, Lu Z, Zipursky SL, Meinertzhagen IA (2010) Drosophila DSCAM proteins regulate postsynaptic specificity at multiple-contact synapses. Neuron 67:761-768. CrossRef Medline

Molyneaux BJ, Arlotta P, Hirata T, Hibi M, Macklis JD (2005) Fezl is required for the birth and specification of corticospinal motor neurons. Neuron 47:817-831. CrossRef Medline

Petersen PH, Zou K, Krauss S, Zhong W (2004) Continuing role for mouse
Numb and Numbl in maintaining progenitor cells during cortical neurogenesis. Nat Neurosci 7:803-811. CrossRef Medline

Polleux F, Ghosh A (2002) The slice overlay assay: a versatile tool to study the influence of extracellular signals on neuronal development. Sci STKE 2002:pl9. Medline

Polleux F, Morrow T, Ghosh A (2000) Semaphorin 3A is a chemoattractant for cortical apical dendrites. Nature 404:567-573. CrossRef Medline

Porrero C, Rubio-Garrido P, Avendaño C, Clascá F (2010) Mapping of fluorescent protein-expressing neurons and axon pathways in adult and developing Thy1-eYFP-H transgenic mice. Brain Res 1345:59-72. CrossRef Medline

Purpura DP (1975) Normal and aberrant neuronal development in the cerebral cortex of human fetus and young infant. UCLA Forum Med Sci 18:141-169. Medline

Rahmani Z, Blouin JL, Creau-Goldberg N, Watkins PC, Mattei JF, Poissonnier M, Prieur M, Chettouh Z, Nicole A, Aurias A, Sinet PM, Delabar JM (1990) Down Syndrome critical region around D21S55 on proximal 21q22.3. Am J Med Genet 7:98-103. CrossRef Medline

Romand S, Wang Y, Toledo-Rodriguez M, Markram H (2011) Morphological development of thick-tufted layer $\mathrm{v}$ pyramidal cells in the rat somatosensory cortex. Front Neuroanat 5:5. Medline

Sago H, Carlson EJ, Smith DJ, Kilbridge J, Rubin EM, Mobley WC, Epstein CJ, Huang TT (1998) TsICJe, a partial trisomy 16 mouse model for Down syndrome, exhibits learning and behavioral abnormalities. Proc Natl Acad Sci U S A 95: 6256-6261. CrossRef Medline

Serafini T, Kennedy TE, Galko MJ, Mirzayan C, Jessell TM, Tessier-Lavigne M (1994) The netrins define a family of axon outgrowth-promoting proteins homologous to C. elegans UNC-6. Cell 78:409-424. CrossRef Medline

Shen H, Sesack SR, Toda S, Kalivas PW (2008) Automated quantification of dendritic spine density and spine head diameter in medium spiny neurons of the nucleus accumbens. Brain Struct Funct 213:149-157. CrossRef Medline

Stein E, Cerretti DP, Daniel TO (1996) Ligand activation of ELK receptor tyrosine kinase promotes its association with Grb10 and Grb2 in vascular endothelial cells. J Biol Chem 271:23588-23593. CrossRef Medline

Tran TS, Rubio ME, Clem RL, Johnson D, Case L, Tessier-Lavigne M, Huganir RL, Ginty DD, Kolodkin AL (2009) Secreted semaphorins control spine distribution and morphogenesis in the postnatal CNS. Nature 462:1065-1069. CrossRef Medline

Wang J, Zugates CT, Liang IH, Lee CH, Lee T (2002) Drosophila DSCAM is required for divergent segregation of sister branches and suppresses ectopic bifurcation of axons. Neuron 33:559-571. CrossRef Medline

Whitford KL, Marillat V, Stein E, Goodman CS, Tessier-Lavigne M, Chédotal A, Ghosh A (2002) Regulation of cortical dendrite development by SlitRobo interactions. Neuron 33:47-61. CrossRef Medline

Xu Y, Ye H, Shen Y, Xu Q, Zhu L, Liu J, Wu JY (2011) DSCAM mutation leads to hydrocephalus and decreased motor function. Protein Cell 2:647-655. CrossRef Medline

Yamagata M, Sanes JR (2008) DSCAM and Sidekick proteins direct laminaspecific synaptic connections in vertebrate retina. Nature 451:465-469. CrossRef Medline

Yamakawa K, Huot YK, Haendelt MA, Hubert R, Chen XN, Lyons GE, Korenberg JR (1998) DSCAM: a novel member of the immunoglobulin superfamily maps in a Down syndrome region and is involved in the development of the nervous system. Hum Mol Genet 7:227-237. CrossRef Medline

Zhou Y, Atkins JB, Rompani SB, Bancescu DL, Petersen PH, Tang H, Zou K, Stewart SB, Zhong W (2007) The mammalian Golgi regulates numb signaling in asymmetric cell division by releasing ACBD3 during mitosis. Cell 129:163-178. CrossRef Medline

Zhu H, Hummel T, Clemens JC, Berdnik D, Zipursky SL, Luo L (2006) Dendritic patterning by DSCAM and synaptic partner matching in the Drosophila antennal lobe. Nat Neurosci 9:349-355. CrossRef Medline

Zhu K, Xu Y, Liu J, Xu Q, Ye H (2011) Down syndrome cell adhesion molecule and its functions in neural development. Neurosci Bull 27:45-52. CrossRef Medline 